Boise State University

ScholarWorks

Psychological Sciences Faculty Publications and Presentations

Department of Psychological Science

$6-2020$

\title{
A Perspective on the Development of Hemispheric Specialization, Infant Handedness, and Cerebral Palsy
}

\author{
Claudio L. Ferre \\ Boston University \\ Iryna Babik \\ Boise State University \\ George F. Michel \\ University of North Carolina at Greensboro
}

\section{Publication Information}

Ferre, Claudio L.; Babik, Iryna; and Michel, George F. (2020). "A Perspective on the Development of Hemispheric Specialization, Infant Handedness, and Cerebral Palsy". Cortex, 127, 208-220.

https://dx.doi.org/10.1016/j.cortex.2020.02.017

This is an author-produced, peer-reviewed version of this article. (c) 2020, Elsevier. Licensed under the Creative Commons Attribution-Noncommercial-No Derivative Works 4.0 International license. The final, definitive version of this document can be found online at Cortex, doi: 10.1016/j.cortex.2020.02.017 


\title{
A Perspective on the Development of Hemispheric Specialization, Infant Handedness, and Cerebral Palsy
}

\author{
Claudio L. Ferre, PhD* \\ Department of Occupational Therapy \\ College of Health \& Rehabilitation Sciences: Sargent \\ College \\ Boston University \\ Boston, MA, USA \\ clferre@bu.edu
}

\author{
Iryna Babik, PhD \\ Department of Psychological Science \\ Boise State University \\ Boise, ID, USA
}

\author{
George F. Michel \\ Department of Psychology \\ University of North Carolina at Greensboro \\ Greensboro, NC, USA
}

\begin{abstract}
Cerebral Palsy (CP), a common form of neurological pediatric disability, results from pre- or perinatal brain injury. Although there is growing evidence of the efficacy of motor learningbased therapies, several factors interact to produce variability in impairment and limit the effectiveness of these therapies. The variability of hand function present in children with $\mathrm{CP}$ indicates that a range of developmental pathways must contribute to the manifestation of individually unique characteristics of impairment. Despite two decades of progress using therapies derived from understanding the mechanisms controlling hand function, very little is known about the sensorimotor experiences occurring during development that likely shape later functional problems for children with CP. We propose that the study of the development of motor skills in typically developing infants may reveal experiential factors potentially important for creating remedial therapies for children with CP. Specifically, we use the development of infant handedness, a model of hemispheric specialization of function, as an example of how selfgenerated experiences and sensorimotor feedback can shape the development of limb control and hemispheric specialization. We illustrate how early sensorimotor asymmetries concatenate into pronounced differences in skill between the two hands. We suggest that this model of infant handedness provides a framework for studying the individual differences manifested in children with CP. These differences likely arise from aberrant sensorimotor experiences created by sensorimotor circuits disrupted by the early brain injury. We conclude that knowledge of the developmental events, including subtle motor behaviors, that shape sensorimotor pathways, can improve treatment options for children with CP.
\end{abstract}

Keywords: cerebral palsy, sensorimotor development, handedness, hemispheric specialization

Cerebral palsy (CP) is a label for a group of relatively non-progressive developmental disorders of postural control and limb movement which arise as a consequence of a disturbance to the developing fetal or infant brain (Mutch et al., 1992; Rosenbaum et al., 2007). Labeling CP as a "group" of disorders marks the general consensus that the underlying etiology and severity of impairments can be quite variable across children (Rosenbaum et al., 2007). This heterogeneity is reflected in the surprisingly large range of functional disabilities across individuals, even within subcategories of CP (Palisano et al., 1997).

Classification of CP is often based on those parts of the body exhibiting movement limitations. The most common form of CP is unilateral cerebral palsy (UCP) in which movement limitations occur primarily on one side of the body as a result of brain injury contralateral to the impaired limbs. A major challenge for children with UCP is upperextremity impairments that limit object manipulation (particularly bimanually coordinated manipulation) which concatenates into loss of personal independence and a sense of reduced quality of life (Russo et al., 2008). Also, as we note later, UCP can have profound consequences on hemispheric specialization of function. Despite considerable 
This is an author-produced, peer-reviewed version of this article. The final, definitive version of this document can be found online at Cortex, published by Elsevier. Copyright restrictions may apply. doi: 10.1016/j.cortex.2020.02.017

progress in the development of therapies aimed at improving upper-extremity function in children with UCP, individual and environmental factors interact to constrain the degree to which children respond to established therapies (Ferre \& Gordon, 2017).

Fortunately, the ways that the development of individual characteristics shapes responsiveness to therapy are becoming clearer. For example, the type of corticospinal reorganization that occurs following brain insult influences the severity of hand impairments (Carr, Harrison, Evans, \& Stephens, 1993) and likely the efficacy of certain forms of therapy (Islam et al., 2014; Kuhnke et al., 2008). Integration between motor areas, via interhemispheric connections, may also affect functional outcomes (Weinstein et al., 2014). Additionally, there is growing empirical evidence that the sensory impairments (e.g., haptic, proprioceptive, kinesthetic) common in children with UCP may play a larger role in motor outcome than previously considered (Bleyenheuft \& Gordon, 2013; Gupta et al., 2017). These examples highlight only a fraction of the factors that shape the degree to which children can benefit from therapy.

Indeed, therapy (including the use of an exoskeleton - a device that facilitates movement) is generally based on trying to duplicate typical development with the presumption that the development of movement control has wide-ranging consequences on cognitive, social, and emotional development. Yet, little is known about how typical motor development contributes to the development of these other psychological functions. Also, little is known about the range of individual differences that arise during ontogeny and the role that these play in typical development or in responsiveness to therapy. For therapy, questions emerge such as: why do children who experience similar brain injuries during the same stage of development display strikingly different functional outcomes later in childhood and adolescence; or are there sensorimotor experiences, or some lack thereof, that produce these unique behavioral developmental profiles?

Surprisingly, despite CP being formalized as a developmental disorder, there are few developmental studies in infants at-risk or diagnosed with CP (Boyd et al., 2013). There is a growing body of literature of diagnostic studies during early development but few are tracking infant sensorimotor experience and development across age. This is a major dilemma for treatment because understanding the types of sensorimotor experiences that shape early neuromotor development might provide insight into the mechanisms that produce individual differences in their responsiveness to therapy for children and adolescents with developmental disorders such as CP (Michel, 2012). Therapeutic techniques to improve upper extremity functions that are guided only by intuitive notions about, and casual observations of, typical upper extremity actions may inadvertently miss more subtle, yet important, influences. Or even, worse, techniques adapted from older children (and even adults) and applied to infants may disrupt important activitydependent processes intimately involved in both sensorimotor and cognitive development. Of course, more research with atypically developing infants would reveal more ways of improving upper extremity function; however, there is also much insight to be gained from focusing inquiry on the types of experiences that shape typical neuromotor development, especially that controlling the arms and hands.

This argument is perhaps best illustrated by experimental studies that focus on the early emergence of motor skills in healthy infants. Understanding the ways mechanisms of motor learning operate during early typical development can provide clinical researchers with insight about the types of experiences that infants developing in the context of a brain injury might be missing. Careful scrutiny of typically occurring events might uncover experiential factors that are not intuitively obvious (Michel, 2007), bear little resemblance to customary notions of learning (Michel, 2010; Smith \& Gasser, 2005), and may appear to be functionally discontinuous with the behavioral system under study (Bekoff, 1992). General developmental principles can be extracted from these studies of typical development that could inform clinicians about how best to optimize early intervention or promote early experiences critical for proper development of motor skills.

The goal of this special issue is to examine the relation between hemispheric specialization and various types of developmental dysfunction. Therefore, our purpose in this manuscript is to reveal how typical differences in handedness development during infancy and early childhood may contribute to the development of hemispheric specialization not only for hand control but also for speech control. We believe that our understanding of handedness development can illuminate factors important for improving the development of infants and children with motor dysfunction (particularly disruptions of the control of the arms and hands) characteristic of CP.

This will not be a review of the development of hemispheric specialization, handedness, or their relation because that literature is so extensive that such a review would encompass a multivolume handbook. Moreover, a thorough review of developmental principles is beyond the scope of this paper (see Blumberg, Freeman, \& Robinson, 2009; Hood, 
This is an author-produced, peer-reviewed version of this article. The final, definitive version of this document can be found online at Cortex, published by Elsevier. Copyright restrictions may apply. doi: 10.1016/j.cortex.2020.02.017

Halpern, Greenberg, \& Lerner, 2010 for recent reviews of development). Rather, we begin by describing how we define the notion of hemispheric specialization of function and the development of handedness. Specifically, we highlight the important role that self-generated experiences and sensorimotor feedback play in shaping the development of limb control and hemispheric specialization. We propose that individual differences in the manifestation of CP and responsiveness to therapy might arise as a consequence of unique developmental trajectories shaped by early sensorimotor experiences. We argue that a major gap in the study of children with CP is ascertaining the ontogenetic consequences of perinatal brain injury in terms of its disruptive effect on sensorimotor experiences during development.

\section{Hemispheric Specialization and Its Implications}

Hemispheric specialization in humans is not a recent feature in evolution (Vallortigara \& Rogers, 2005). According to some, it evolved in humans from neural systems responsible for intentional grasping in nonhuman primates to allow for complex manual actions (praxis) and gestural (and subsequently speech) communication. As hominins achieved bipedal locomotion, which freed the hands for sophisticated tool use, the increased demands for complex information processing facilitated more elaborate lateralization (Corballis, 2015). Specialization of the two hemispheres increases the information processing efficiency by allowing parallel processing, decreasing duplication, and eliminating potential interhemispheric conflict (Corballis, 1991, 2017; Güntürkün \& Ocklenburg, 2017; Rogers, Zucca, \& Vallortigara, 2004). Thus, specialization improves current utility and perhaps survival of the individual (MacNeilage, Rogers, \& Vallortigara, 2009; Rogers, Vallortigara, \& Andrew, 2013).

For most people, the left hemisphere is responsible for distinguishing phonological differences of language-related sounds and is important for producing those phonological distinctions during speech. In contrast, the right hemisphere is better at processing environmental noises, melodies, rhythms, and the emotional prosody of speech (Gardner, Brownell, Wapner, \& Michelow, 1983; Gazzaniga, Ivry, \& Mangun, 2009; Kimura, 1973). Again, for most people, left hemisphere is better at facial recognition and generation of voluntary facial movements, whereas the right hemisphere is better at differentiating faces from non-faces (Gazzaniga et al, 2009). Also, for both infants and adults, the left hemisphere displays greater activation in response to positive "emotional" stimuli, whereas negative "emotional" stimuli result in higher 42 activation of the right hemisphere (Davidson, 1992; Demaree, Everhart, Youngstrom, \& Harrison, 2005). Nevertheless, it is generally acknowledged that the gross anatomical, physiological (neurotransmitter actions and synaptic processes), and functional differences between the hemispheres are more a matter of degree rather than kind.

A hand-use preference for certain types of manual skills and the control of speech functions are the most clearly distinct differences between the hemispheres and are often characterized as categorical. As we noted, for most people, the left hemisphere controls the production and comprehension of speech. Since the contralateral hemisphere controls the sort of manual actions that contribute to a hand-use preference and since most people across different cultures exhibit a right-hand preference, speech and handedness are predominantly associated with left hemisphere and often with each other. Various explanations have been proposed for this association, including: handedness derives from hemispheric specialization for speech; speech lateralization derives from handedness development; both derive from specialization for some other character; they are only coincidentally associated because they are both controlled by the left hemisphere. At present, there is no way of empirically adjudicating among these alternatives. However, it is important to recognize that individuals vary in their degree of handedness; thus, handedness is not a categorical variable but rather the degree of difference in proficiency and preference between the hands is continuously distributed across the population (with a distinct rightward shift). Without more reliable and discrete measures of hemispheric differences for control of speech across people, it is unknown (but likely) whether hemispheric control of speech and other language abilities also may be continuously distributed across people (with a distinct left-hemisphere shift). It is often reported that about $12 \%$ of a sample of adults have right hemisphere control of language abilities and another $10 \%$ seem to have no distinct hemispheric dominance for language (e.g., Knecht et al. 2000b). Only by specifying exactly what the differences are between the hemispheres, can we elucidate how language and handedness managed to become the two most clearly distinct aspects of hemispheric specialization. Although there is insufficient evidence to do such specification, we, along with others, propose that rather than reflecting functional categories, hemispheric differences reflect forms of information processing that affect pattern perception and motor organization (Deco, Tononi, Boly, \& Kringelbach, 2015). 
This is an author-produced, peer-reviewed version of this article. The final, definitive version of this document can be found online at Cortex, published by Elsevier. Copyright restrictions may apply. doi: 10.1016/j.cortex.2020.02.017

Complex visual, auditory, and haptic stimuli are composed of many spatial and temporal patterns of transitions that are hierarchically organized according to the relative frequency of these transitions (from low to high) across space and time. According to the hemisphere processing-frequency hypothesis (Sergent, 1982b), identifying, comparing and remembering the characteristics of any complex hierarchically structured visual, auditory, or haptic stimulus might depend upon two neuronal systems. One system that is more effective at extracting higher frequency transitions in temporal and spatial patterns and, hence, it is better at distinguishing the sort of subtle details that enable discrimination of speech sounds, individual faces, printed letters, etc. The other system is more effective at processing lower frequency transitions and would be better at extracting the more global, or Gestalt, aspects of the stimulus. According to this hypothesis, analysis of high-frequency transitions (e.g., those needed for detecting phonological distinctions, facial recognition, specific spatial location) is the typical processing ability of the left hemisphere; whereas the analysis of low-frequency transitions (e.g., those needed for detecting emotional tone, rhythm, faces from non-faces, relative position in space) is the typical processing ability of the right hemisphere (Sergent, 1982b).

This differential processing, however, need not mean that the hemispheres are distinctly different in their information processing ability. Rather, both hemispheres are capable of processing information that is in their non-preferred range, but perhaps not as proficiently (Sergent, 1982c). Also, extensive developmental experience of success in the usual processing mode, in combination with interhemispheric inhibition, may constrain the ability of the hemispheres to readily shift modes. Note that frequency and temporal characteristics of stimuli do not always align with clear distinctions of functional organization (e.g., language vs. spatial). It is not always the case that verbal visual information and speech sounds would reveal a left hemisphere processing advantage and visuo-spatial stimuli (a right hemisphere advantage). Rather, the right vs. left ear advantage in dichotic listening tasks would depend on the relative frequency of the presented stimulus (Previc, 1991). For example, the right ear (left hemisphere) advantage would be recorded for the higher of two tones, irrespective of whether they represent speech or noise (e.g., Deutsch, 1985; Efron, Koss, \& Yund, 1983). Similarly, the right hemisphere exhibits an advantage in processing of low frequency information regardless of the stimulus type (Thatcher, 1980). Thus, prosodic characteristics of speech are mostly processed by the right hemisphere because they reflect low frequency transitions (Godfrey \& Grimshaw, 2016). Difference between hemispheres in frequency analysis clarifies the right hemisphere advantage at discriminating a face from non-face stimulus (Levine, Banich, \& Koch-Weser, 1988), and the left hemisphere is better at discriminating two faces that differ in just one feature; the latter presumably requiring a higher spatial frequency analysis (e.g., Patterson \& Bradshaw, 1975; Sergent, 1982a). Also, as a result of developmental experience, the degree of activation in the left-hemisphere temporal cortex depends on experience in a language-based context, rather than just the characteristics of sounds (Shtyrov, Pihko, \& Pulvermuller, 2005). Thus, Zulu language speakers exhibited right-ear (left hemisphere) advantage for processing of click consonants of Zulu language, whereas English speakers did not show this pattern (Best \& Avery, 1999). Also, in tonal languages, correct detection of tonal qualities of speech sounds (usually associated with prosody) is necessary for understanding the meaning of those sounds. Therefore, native Mandarin speakers demonstrated right-ear advantage (left hemisphere) for tonal inflection, whereas English speakers tested on the same stimuli exhibited no asymmetry (Wang, Behne, Jongman, \& Sereno, 2004; Wang, Jongman, \& Sereno, 2001). Although Norwegian language is also tonal, Norwegian speakers exhibited a right-ear advantage for tonal qualities of their language, but not for tonal sounds typical for Mandarin (Moen, 1993; Wang et al., 2004). Thus, neither functional categories nor simple notions about processing strategies (spatial and temporal frequency analysis) characterize the differences between the hemispheres because developmental experiences (with faces, native language sounds, etc.) shape hemispheric differences.

What is missing from this notion that the hemispheres differ in processing hierarchically structured stimulus patterns is that the hemispheres also differ for the construction of actions. That is, the left hemisphere is typically involved in the production of precisely-timed, serially ordered movement patterns that contribute to the articulation of speech sounds, as well as sophisticated manual actions manifested in object manipulation, artifact construction, tool-use, imitating actions, and communicative pantomiming. In contrast, the right hemisphere seems to provide the postural and contextual support for the actions produced by the left hemisphere. Indeed, there are complementary specializations of each hemisphere for different aspects of control in the context of a role-differentiated bimanual manipulation (RDBM) task (Woytowicz, Westlake, Whitall, \& Sainburg, 2018). Again, these differences are relative, not absolute.

Therefore, it is not correct to state that the left hemisphere controls language while the right hemisphere controls visuospatial skills, or that there is a distinct division of labor between the two hemispheres. Rather, both hemispheres potentially are capable of processing any type of information, while the relative spatial or temporal frequency pattern 
This is an author-produced, peer-reviewed version of this article. The final, definitive version of this document can be found online at Cortex, published by Elsevier. Copyright restrictions may apply. doi: 10.1016/j.cortex.2020.02.017

of the information, its complexity, and socio-cultural aspects would determine, to some extent, the hemisphere that may cope with a task more effectively. Both hemispheres may be capable of controlling precisely timed, sequentially organized muscle contractions and relaxations that underlie the ability to manifest serially ordered speech and manual skills; however, the skill differences that come from practice and inhibition mediated by the corpus callosum (CC) reduce the ready transfer of these abilities between hemispheres. As we show later, this has important implication for how therapy is designed for a child having only ipsilateral control of the affected hand.

There are two important caveats for understanding hemispheric specialization. First, the division of labor between the hemispheres has a relative rather than absolute character, with the type of information processing, or action programming, being more important for the distribution of work between the two hemispheres. Second, although structurally and functionally distinct, the two hemispheres are still deeply connected via the corpus callosum: they have access to and can potentially process any type of information. Therefore, the development of callosal functioning ought to be a major concern of developmental studies of hemispheric specialization. How and when different forms of processing control can be shared across hemispheres will greatly affect the development of specialization.

\section{Corpus Callosum and Hemispheric Lateralization}

The CC is the major commissural tract mainly connecting homologous areas in the two cerebral hemispheres and allowing integration of sensorimotor information (Pandya, Karol, \& Heilbronn, 1971; Sperry, 1968). For humans, the formation of CC starts around the 12th week of gestation with all fibers being in place by the 20th week of gestation. By 2 years of age, the size of CC is comparable to the adult one, but the process of myelination that starts around the fourth month of pregnancy continues well into the third decade (e.g., Giedd et al, 1999; Knyazeva \& Faber, 1991; Pujol, Vendrell, Junqué, Larti-Vilalta, \& Capdevila, 1993; Salamy, 1978). In the typically developing brain, the CC presumably allows the extension of available cortical space through the reduction of redundancy in information processing. In this case, the two hemispheres can achieve specialization as long as the CC enables the access to this specialized processing for the entire system.

There have been long debates about the role of the CC in the development of hemispheric asymmetry. It was argued that CC not only permits the transfer of information between the two hemispheres, but also allows inhibition of one hemisphere by the activity that is currently taking place in the other hemisphere (Meyer, Röricht, Gräfin von Einsiedel, Kruggel, \& Weindl, 1995; Schnitzler, Kessler, \& Benecke, 1996). In addition, the under-developed CC in infancy and early childhood may play an important role in the development of hemispheric asymmetries and handedness by restricting the processing of asymmetrical sensorimotor inputs to one hemisphere and, thereby, making it more apt for processing particular types of stimuli and programming particular types of actions (Gazzaniga, 2000; Hellige, 1993; Michel, 1988).

Previous research demonstrated that the development of typical bimanual coordination depends upon the functioning of interhemispheric transfer via the CC (Fagard \& Corroyer, 2003; Jeeves, Silver, \& Milne, 1988; Preilowski, 1975). With an intact CC, children with UCP may be able to accomplish bimanual coordination via an appropriately designed therapy. Moreover, even a poorly functioning CC may be adjusted enough via therapy to permit bimanually coordinated actions. This would greatly improve children's manual engagement with objects.

\section{The Relation of Handedness to Hemispheric Specialization for Language}

Identification of the relation of handedness to speech lateralization requires better assessments of both handedness and speech (Peelle, 2012). As noted above, how hemispheric specialization is characterized greatly influences how we understand what is different between the hemispheres and how that relates to other ways that the nervous system functions. Descriptions of differences in information processing strategies and motor programming typically have not been used when examining the relation of hemispheric specialization to other functions. Moreover, very little research attention has been invested in examining how specialization develops. Indeed, many (e.g., Kinsbourne, 1975; Witelson, 1985) have considered hemispheric specialization to be present at birth (presumably established by genetic mechanisms operating prenatally) or to develop via endogenously controlled maturational processes uninfluenced by prenatal or postnatal experience (Lenneberg, 1967). Unfortunately, most research on hemispheric specialization is conducted with adults and presumes that any developmental processes have ended after the second decade and the only further change occurs with deterioration. We have tried to correct some of that by studying the early development of the hemispheric specialization that is manifest in a hand-use preference. 
This is an author-produced, peer-reviewed version of this article. The final, definitive version of this document can be found online at Cortex, published by Elsevier. Copyright restrictions may apply. doi: 10.1016/j.cortex.2020.02.017

Previous research showing a strong relation of left-hemisphere dominance for language and handedness was conducted primarily on self-assigned right-handed adults. However, when self-assigned left-handers were studied, the relation between handedness and language lateralization became confusing. Now, it is generally presumed that 95$97 \%$ of right-handers and $70-81 \%$ of left-handers exhibit left-hemisphere dominance for language processing (Badzakova-Trajkov, Häberling, Roberts, \& Corballis, 2010; Bethmann, Tempelmann, De Bleser, Scheich, \& Brechmann, 2007; Isaacs, Barr, Nelson, \& Devinsky, 2006; Knecht et al., 2000a, 2000b). But why do some 3-5\% of right-handers and some $19-30 \%$ of left handers not show left hemisphere language dominance? Perhaps, this is because studies relating handedness to language lateralization most often relied on self-reported handedness, or hand used for writing, or scores on the Edinburgh questionnaire (Oldfield, 1971); however, these measures are poorly related to proficiency differences between the hands (cf., Michel, Nelson, Babik, Campbell, \& Marcinowski, 2013). Also, assessment of the relation in adults may not reflect the role that handedness plays in the development of hemispheric specialization for speech control (Michel, 1988) - that issue requires further developmental investigations.

It would be surprising if motor and speech asymmetries did not share some neural networks (especially early in development), since both require accurate sequencing and timing processes (Abbs \& Grecco, 1983; Ojemann, 1984). Indeed, handedness might serve as a convenient marker of hemispheric specialization for speech control and perception (Corballis, 2010; Serrien, Ivry, \& Swinnen, 2006). Also, the notion that tool-use (highly influenced by handedness) and language have common developmental origins (Frey, 2014) is consistent with the popular theory about coevolution of tool-use and language in humans (e.g., Steele \& Uomini, 2009; Uomini \& Meyer, 2013). However, convincing evidence relating handedness to communicative gestures and language is still missing and will depend upon accurate descriptions of hemisphere differences in speech comprehension and production and in accurate assessments of proficiency differences between the hands.

Casasanto (2009) proposed that the relation between handedness and language might be studied in the ways action words are processed by the brain. His body-specificity hypothesis claims that right-handed and left-handed people should process action words in different hemispheres. Indeed, neuroimaging studies found activation in the left premotor areas in right-handers and right premotor areas in left-handers processing manual action verbs, such as "grasp" and "throw" (Willems, Hagoort, \& Casasanto, 2010; Willems, Toni, Hagoort, \& Casasanto, 2010). Willems concluded that lateralization for processing action verbs is closely related to the neural networks engaged in the performance of manual actions. Unfortunately, handedness in these studies was not identified by proficiency differences.

There is much evidence that the development of left-hand preference is not the mirror image of the development of right-hand preference (Michel et al., 2013b); indeed, there are several trajectories exhibited during the early development of a hand-preference. Therefore, sample sizes need to be very large to have the power to identify whether any hand preference directly relates to the development of any cognitive ability (Michel, 2018). Although Casasanto's hypothesis predicts that a hand preference ought to relate to many cognitive abilities, the effects of the trajectory differences in the way by which various forms of right and left handedness develop must be examined because it is likely that those trajectory differences create differences in cognitive ability (Nelson, Gonzalez, Coxe, Campbell, Marcinowski, \& Michel, 2017).

Speech has an obvious gestural accompaniment that contributes to comprehension (Goldin-Meadow \& McNeill, 1999; McNeill, 2012; Willems \& Hagoort, 2007) and the accompanying gestures may be crucial in speech development (Bates \& Dick, 2002). Word comprehension and production at the age of 8-13 months is often accompanied by pointing gestures (Bates \& Dick, 2002). Early manual gestures also predict later success in speech production (Iverson \& Goldin- Meadow, 2005). However, despite a widely reported right-hand preference for pointing gestures (e.g., Esseily, Jacquet, \& Fagard, 2011; Franco \& Butterworth, 1996), hand preference for communicative gestures has not been consistently related to that for manual actions (e.g., Bates, O’Connell, Vaid, Sledge, \& Oakes, 1986; Jacquet, Esseily, Rider, \& Fagard, 2012; Ramsay, 1985; Vauclair \& Imbault, 2009). Unfortunately, in many of these studies, hand preferences were derived from simple differences in use of the hands without assessment of the statistical likelihood of the actual hand preference (Campbell, Marcinowski, Latta, \& Michel, 2015b).

Sign languages are predominantly manual and activate the typical language areas in the left hemisphere (Emmorey et al., 2003; Emmorey, Mehta, \& Grabowski, 2007; Petitto et al., 2000; San José-Robertson, Corina, Ackerman, Guillemin, \& Braun, 2004) with left-hemisphere damage leading to sign-language aphasia in deaf individuals (Corina, 
This is an author-produced, peer-reviewed version of this article. The final, definitive version of this document can be found online at Cortex, published by Elsevier. Copyright restrictions may apply. doi: 10.1016/j.cortex.2020.02.017

1998; Hickok, Bellugi, \& Klima, 1998; Marshall, Atkinson, Smulovitch, Thacker, \& Woll, 2004). Unfortunately, such studies have not examined individuals with different handedness; albeit most sign-languages have a distinct righthand bias in use.

Some have proposed a connection among the development of early manual sensorimotor skills (object manipulation, construction of artifacts, tool-use), manual communication skills (imitation of manual actions), and gestural speech skills (imitation of speech sounds) via a mirror neuron system (Arbib, 2006; Oztop, Arbib, \& Bradley, 2006). Thus, manual sensorimotor skills might provide the foundation for the production of speech gestures and language (Arbib, 2006, 2011; Greenfield, 2006; Michel, Babik, Nelson, Campbell, \& Marcinowski, 2013a). As a result, one might predict a strong relation between handedness and communicative gestures. However, research results seem contradictory; again, likely because of poor measurement techniques for assessing handedness and other forms of hemispheric specialization via developmental investigations (cf., Michel et al., 2013a).

\section{Early Development of Handedness}

Humans typically prefer to use a specific hand for complex manipulative actions and the other hand for actions that complement and support those of the other hand - a form of role-differentiated bimanual manipulation (RDBM). The distribution of these hand preferences is quite consistent across all populations with an overwhelming majority demonstrating a preference to use their right hand for both attention-intense and habitual unimanual actions. This preference, known as handedness, reflects hemispheric specialization in manual control and emerges during the first postnatal year (Ferre, Babik, \& Michel, 2010). The relative robustness of the behavior has led some to conclude that manual behaviors reflect the sequential maturation of discrete reflexes and higher-order cortical control. However, detailed longitudinal study of manual behaviors has provided evidence for the importance of self-generated experiences and a cascade of developmental events (Michel, 2007).

Understanding how motor control emerges throughout the course of development requires characterization of the multiple factors that interact to permit the expression of coordinated movements (Brumley \& Robinson, 2010). These factors include: neural resources that must exist to generate organized movement, interactions between neural and biomechanical systems that constrain and shape movement, and interactions between the individual and the environment in which movement is expressed. Since the foundations of a behavior or motor skill are established early in development and may bear little resemblance to its later functional appearance, characterizing the influence of these three factors is challenging. Thus, the task of the researcher interested in identifying developmental antecedents is to find creative ways to track behavior that is manifested in distinct forms over time and to identify relevant experiences shaping the trajectory of such behavior.

For example, neonatal rats are capable of expressing organized movement patterns immediately after birth-a remarkable feat considering that rat pups must be able to generate specific spatial and temporal relationships between the limbs and overcome novel biomechanical challenges in a postnatal environment quite distinct from the intrauterine environment. However, many patterns of functional postnatal behavior have their roots in the prenatal period (Robinson, 2016). Using fetal animal models, it has been shown that changes in limb flexion-extension patterns are shaped by interactions among spinal neuronal activity (Kudo, Nishimaru, \& Nakayama, 2004), biomechanical constraints such as gravitational load (Bradley, 1997) as well as the flexibility of uterine wall (Robinson, 2016), proprioceptive feedback (Ronca, Kamm, Thelen, \& Alberts, 1994), and spontaneous muscle activation (Brumley \& Robinson, 2010).

Using a technique in which a fetus is externalized and the hindlimbs are yoked together by a physical linkage, studies have shown that kinesthetic feedback can be altered, so that the active movement created by one limb during spontaneous motility produces passive conjugate movements of the yoked limb (for review see Robinson, 2016). With such training, changes in interlimb coordination are produced that persist even after the physical yoke is removed, suggesting evidence of very early motor learning or at least the spinal organization of coordination. That this form of motor learning occurs suggests that the fetal nervous system can detect the presence of the physical linkage, produce self-generated kinesthetic signals during spontaneous activity, and modify motor output to produce coupled interlimb movements. The change in frequency and organization during the last few days of gestation in the intact rat fetus provide evidence that they may be equally responsive to such contingencies even while in utero (Kleven, Lane, \& Robinson, 2004). 
This is an author-produced, peer-reviewed version of this article. The final, definitive version of this document can be found online at Cortex, published by Elsevier. Copyright restrictions may apply. doi: 10.1016/j.cortex.2020.02.017

The interaction between sensory feedback and spontaneous motility drive the progressive reorganization from a "loosely" structured motor behavior of the fetus to a more elegantly coordinated action systems of the newborn. It is conceivable that human fetuses can also discover patterns of interlimb coordination early in development. The neural mechanisms producing postnatal alternating leg flexions and extensions (step-like patterns) likely begin in utero and are expanded over the course of development (Thelen, Fisher, \& Ridley-Johnson, 2002). The biomechanics of the uterine wall's flexibility permits greater extension of each limb when their movements are alternated as opposed to when they occur simultaneously (Robinson, 2016). This likely contributes to the development of alternating limb movements. Thus, the developmental processes promoting walking coordination begin prior to the age when walking is functional and is expressed with non-intuitively obvious patterns (i.e., spontaneous movements in utero). The existence of these developmental precursors to walking might afford an early, opportune time to intervene for those at risk for CP (Teulier, Lee, \& Ulrich, 2015).

As illustrated in the examples above, the developmental origins of handedness might begin with patterns quite distinct from its later functional form. However, it has been proposed that hand-use preference may be observed as early as 10-15 weeks of fetal development when fetuses appear to make hand contact with the head, preferentially suck one thumb, and exhibit preferential arm movement (Hepper, Shahidullah, \& White, 1991). By examining brief ultrasounds collected from hundreds of women at various points during the pregnancy, it seemed that the majority of fetuses (85\%) exhibit more arm movements on the right side than the left side at 10 weeks of gestation (Hepper, McCartney, \& Shannon, 1998). By the 15th week of gestation, $80 \%$ of fetuses sucked their right thumb and $20 \%$ sucked their left thumb (Hepper et al., 1991). Moreover, prenatal thumb-sucking was significantly related to the hand-use preference of 75 children at $10-12$ years with $100 \%$ of right thumb-sucking fetuses being righthanded pre-teens and $67 \%$ of left thumb-sucking fetuses being left-handed and 33\% becoming right-handed (Hepper, Wells, \& Lynch, 2005) - an almost perfect result.

Clearly, this work needs replication because those brief 2D ultrasounds collected during the 1970s and 1980s did not provide accurate ways of assessing orientation of fetal limbs relative to other body parts (see Hopkins \& Ronnqvist, 1998; Michel, 1983). Using one-hour ultrasounds recorded more than 12 times from the same 10 fetuses during the 12-38 weeks of the pregnancy, de Vries et al. $(1982,2001)$ did not find any lateralized preference of unimanual handhead contacts or any lateralized differences in arm movements; however, there were asymmetries of head turning during the last trimester. Moreover, a right-side bias in fetal head orientation was observed during the last trimester using real-time ultrasound (Verves, de Vries, van Geijn, \& Hopkins, 1994).

It would not be surprising if the origins of handedness resided in early fetal asymmetrical biases, such as fetal posture and position in utero. Intrauterine position is considered to be a major contributor to the organization of postnatal posture and reflexes (Sival, Prechtl, Sonder, \& Touwen, 1993). The size, shape, and specific gravity of the fetus combine with the shape of the uterus and pelvic ring to restrict movement and position of the fetus in the uterus. One of the consequences of this positioning (and the human bipedal locomotion pattern) is an asymmetry in prenatal vestibular and auditory experience (Previc, 1991). In humans, the asymmetrical character of the uterus in combination with the specific gravity of the fetus create conditions that result in one position (i.e., inverted fetus with the back to mother's left side) being more probable than the other.

The positioning of the fetus results in an asymmetry of exposure to environmental speech sounds (right ear having greater exposure) and greater leftward stimulation of the otolith organs as a consequence of the mother's forward locomotion movements. In rodents, surgical manipulation of vestibular function in one ear creates a lateral bias in motor function and the neural pathways that regulate motor activity (Antoine et al., 2018). That is, asymmetrical sensory input to the vestibular system results in a pronounced motor asymmetry. The asymmetry in stimulation of the otoliths during the fetal period has been proposed to create a bias in neonatal head orientation preference (HOP; Fong, Savelsbergh, van Geijn, \& de Vries, 2005; Michel \& Goodwin, 1979). That is, during the first two months of life, a majority of infants prefer to lie with their heads to the right when supine, with only 12-14\% preferring a leftward HOP (Michel \& Goodwin, 1979). The HOP preference creates a lateral asymmetry of visual regard of the limbs and an asymmetry in limb movements. That is, infants have greater visual exposure to, and show a greater frequency and range of movements of the limb that is ipsilateral to the direction that the face is turned (Michel \& Harkins, 1986). Thus, a bias in head orientation preference of neonates creates the conditions for a lateral bias in both hand regard and activity of the hand (with consequent lateral asymmetry of proprioceptive, kinesthetic, and haptic feedback). 
This is an author-produced, peer-reviewed version of this article. The final, definitive version of this document can be found online at Cortex, published by Elsevier. Copyright restrictions may apply. doi: 10.1016/j.cortex.2020.02.017

The lateral bias in sensorimotor experience among neonates predicts subsequent hand-use preferences in reaching for and manipulating objects during the age period of 5 to 18 months (Michel, 1991). That is, infants with an early left HOP are more likely to demonstrate a left-hand preference for reaching at later ages, whereas those with an early right HOP are more likely to demonstrate a right-hand preference. Thus, HOP may be associated with handedness as a result of sensorimotor differences in visuo-motor, kinesthetic, and proprioceptive experience of the hands. A hand preference for reaching for and obtaining objects results in differences between the hands (and the contralateral hemisphere because of an under-developed CC) in haptic experience, hand-to-mouth actions, and visual regard of the hand and objects. The non-preferred hand often contacts the preferred hand during object acquisition, which results in the nonpreferred hand having more experience in complementing and supporting the actions of the preferred hand.

Following an initial period of 6-9 postnatal months in which there are no hand differences in the manipulation of objects that are placed in both of the infant's hands, the hands begin to differentiate their manipulation skills with the preferred hand for acquisition predicting the hand preference for unimanual manipulation of objects (Campbell, Marcinowski, Babik, \& Michel, 2015b). These differences in unimanual actions (acquisition and object manipulation) likely culminate in a hand preference for RDBM early in the second postnatal year (see Babik \& Michel, 2016). By 18 months, toddlers are engaging primarily in RDBM with objects and a toddler's hand-use preference for RDBM is predicted by his/her hand-use preference for acquiring objects as infants (Nelson, Campbell, \& Michel, 2013b).

Thus, handedness is not emerging independently in any succession of more complex manual skills. Instead, handedness for simple reaching for objects expands into handedness for acquiring objects which, in turn, transfers into hand-use preferences in later-emerging skills such as unimanual manipulation and RDBM (Michel et al., 2013b). At each phase, self-generated haptic, proprioceptive, kinesthetic, and visual experience contribute to the transitions in how a hand-use preference is manifested. Also, the manifestation of hand-use preferences for a manual skill will vary with the development of that skill; with lateralization being low at the emergence of the action, increasing as the skill becomes mastered, and then decreasing as the action becomes highly skilled and more automatic (Michel et al., 2013b). Thus, to assess handedness during infancy, the tasks must be sufficiently difficult to elicit a preference, but not too difficult.

The sequence from asymmetry of vestibular stimulation in utero, to asymmetry of sensorimotor experiences created by neonatal postures, to emergence of initial hand preferences for acquiring objects, to the cascade of hand preferences to unimanual and RDBM actions suggest that the spontaneous behavior of neonates both reflects and contributes to the development of neurobehavioral organization during infancy. Infants, through their spontaneous behavior and selfgenerated exploration of the environment, play an active role in their own neuromotor development. Experiences at earlier stages of development provide the organization of a neuromotor substrate upon which subsequent stages would build. Sensory experiences in one domain (e.g., visual regard) can guide the emergence of functions in other domains (e.g., reaching; Barrett, Traupman, \& Needham, 2008; Corbetta \& Snapp-Childs, 2009; McCarty \& Ashmead, 1999; Rochat \& Bullinger, 1994). Subtle environmental differences and spontaneous behavior interact to create small variations in individual experiences-variations that can lead to large individual differences in motor function later in life (Cioni et al., 1997; Corbetta, Thurman, Wiener, Guan, \& Williams, 2014; Fetters, Sapir, Chen, Kubo, \& Tronick, 2010; Thelen et al., 1993; Thomas, Karl, \& Whishaw, 2015). Thus, the challenge for the investigator of development is to identify the presence of these early experiences and reveal their contribution to the development of motor skills. This marks an important consideration for therapeutic techniques for the treatment of CP.

Studies of typically developing infants suggest that self-generated, spontaneous movements at early stages provide the substrate for subsequent motor skills. Spontaneous movements contribute to motor skills by: 1) creating topological representations in the brain and spinal cord that are necessary for perception and motor control, and 2) shaping the organization of primary motor and sensory pathways. Self-generated neonatal motor activity induces a combination of tactile, kinesthetic, proprioceptive, and vestibular input that allows infants to refine sensorimotor circuits. Although clinicians use the quality of spontaneous movement for classification purposes of infants at high risk of developing $\mathrm{CP}$, little is known about what these movements are providing for the development of the neural substrates (including lateral biases).

\section{The Contribution of the Development of Handedness to Hemispheric Specialization}

Michel (1983, 1988, 1998, 2002) proposed a modified progressive lateralization (MPL) theory, which recognized that many structural, physiological, and functional asymmetries can be observed very early (perhaps as early as the first division of the zygote; Morgan, 1977) and these are involved in the initial development of the nervous system. 
This is an author-produced, peer-reviewed version of this article. The final, definitive version of this document can be found online at Cortex, published by Elsevier. Copyright restrictions may apply. doi: 10.1016/j.cortex.2020.02.017

However, hemispheric specialization continues to develop throughout infancy, childhood, adolescence, and even adulthood. According to this theory, the development of hemispheric specialization of function involves a cascading sequence of developmental events in which early forms of lateral asymmetries contribute to the development of later forms, and the later forms may continue to build upon the earlier. Although this cascading effect constrains development along a particular trajectory, the trajectory is not inevitable. Thus, initial zygotic asymmetries would couple with initial asymmetries of the intrauterine environment to produce the earliest stages of the progressive development of hemispheric specialization. In this approach, it is possible for the hemispheric differences in degree of information processing to be altered at different points in the developmental trajectory. Unfortunately, the sort of events that can alter these trajectories is currently unknown.

Previously, we specified the manner by which the development of hand-use preferences could contribute to the development of hemispheric specialization for speech (Michel et al., 2013a). However, that argument was rather critical of typical measures of both handedness and of hemispheric specialization of function. We proposed (along with others, see Arbib, 2006, 2011; Corballis, 2003; Greenfield, 2006) that the development of sensorimotor skills in manual actions may be the foundation of language skills and their lateralization. Manual skill, gestural communication, and speech acts depend upon finely timed transitions between appropriately ordered sequences of acts (Abbs \& Grecco, 1983). Moreover, the decoding of heard speech seems to depend upon the sensorimotor skills needed to produce it (Liberman \& Mattingly, 1985). Speech phonology exhibits a rule system similar to both the rule system in the control of manual gestures and that in the organization of the syntax of language (Cooper \& Paccia-Cooper, 1980). Therefore, the programming of speech may derive, in part, from the programming of manual actions, whereas the programming of manual actions would derive from experience, likely those associated with the control of a preferred hand. Perhaps, by this set of connections, the development of handedness (as measured by proficiency only) contributes to the development of speech processing and its lateralization in the hemisphere contralateral to the preferred hand.

\section{Developmental Concepts Relevant to Understanding Cerebral Palsy}

Development is a historical process in which previous events affect the manifestation of both current and subsequent events, and current events, in turn, become the previous events that affect subsequent events. Hence, there is a serial order to developmental phenomena that creates a trajectory of morphological and physiological phenotypes that can be individually specific while retaining species typicality (Kolb \& Teskey, 2012). Consequently, development should be defined by identifying the factors creating and governing the serial order of the trajectory; specifying the processes that produce both change and stability of that order over time and across individuals (Michel \& Moore, 1995). Once developmental trajectories of particular phenotypes are specified, we can use these to discover how recovery might be accomplished.

Often, during development of any specific function, a particular phase in the serial order may appear to be more critical to a typical developmental outcome than another phase. This phase is often defined as a critical or sensitive period (Michel \& Tyler, 2005). Indeed, the development of CP seems to reflect disruption of brain development during a critical period. However, a critical or sensitive period for the occurrence of CP should not be taken as evidence of a critical or sensitive period for recovery of function; these are different, albeit related, phenomena (Michel, 2012). A developmental period for CP is considered "critical" partly because it is difficult to create CP by perturbations later in development and partly because it is more difficult to correct the CP by manipulations later, rather than earlier, in development.

Although "age"' appears to be the defining characteristic of the concept of critical period, central to its investigation is the recognition that there are specific events which must occur in a particular order for the typical development of subsequent characteristics to occur (Michel \& Tyler, 2005). Once the sequence of developmental events has occurred, it may be difficult to alter, compensate for, or reestablish the typical developmental trajectory, and this leads to an atypical phenotype. Nevertheless, knowledge of the typical developmental trajectory of neuromotor functioning is essential for understanding of what went wrong in the development of CP and this knowledge may be used to identify clever ways of re-establishing a more typical trajectory and outcome later in the lifespan (i.e., recovery).

Since the concepts used to characterize neural development, the phenomena of neural plasticity, and recovery of function after neural damage mark many different processes (Kolb \& Teskey, 2012), we must be cognizant of these differences in order to avoid confusion and the inappropriate application of our knowledge. Neural development is: 1) multiple trajectories creating morphological and physiological variability both in the steps comprising the 
This is an author-produced, peer-reviewed version of this article. The final, definitive version of this document can be found online at Cortex, published by Elsevier. Copyright restrictions may apply. doi: 10.1016/j.cortex.2020.02.017

trajectory and in the endpoint of the trajectory; 2) equifinality in which multiple trajectories converge on a similar endpoint; 3) sequentially organized steps in which certain earlier phenotypes must be completed before subsequent phenotypes can occur-this sequential character is usually marked by critical periods in the developmental history; 4) regression in which certain levels of organization are disrupted before developmental reorganization can occur.

In contrast, neural plasticity in recovery of function is marked primarily by phenomena identified as learning and usedependent organization or practice (Corbetta, 2012; Kolb \& Teskey, 2012). Recovery of function involves: 1) changes in brain organization needed to compensate for a missing function; 2) brain plasticity; and 3) developmental processes. Thus, recovery of function refers to the consequences of neural damage in which processes of learning and practice must combine with developmental processes of multiple trajectories, regression, and the sequential dependency of transformations in phenotypic expression to constrain or promote the neural reorganization.

Recovery can mean the reestablishment of lost abilities or skills (remediation) or, more frequently, the compensation of such loss by using alternative strategies. Too often, rehabilitation therapies for patients with brain damage focus on ways to circumvent the deficits (compensation) rather than the remediation of deficits (Small, Boccino, \& Solodkin, 2012). Compensation is considered the most efficient way to achieve "recovery". In compensatory recovery, different behaviors are used to meet environmental needs (e.g., in infants with CP, an exoskeleton may be employed), and functional restoration is bypassed. In remediation, the lost behavior is actually restored, rather than circumvented. However, compensation is often cheaper, quicker, and currently more reliable. Therefore, it becomes the preferred approach for insurers, therapists, as well as patients and their families.

Also, we know too little about the typical processes of development to devise remediation therapies that are likely to be reliably successful. We need to obtain information about which mechanisms maintain developmental trajectory stability (e.g., hormonal condition, both intraand inter-hemispheric activity-dependent neural circuits) which make recovery from stroke more difficult in adults than in children. And we need to know how neural circuits for behaviors are stablished and maintained during development, so that we can determine whether the circuits needed for recovery must be established and maintained in the same manner as they were during development.

\section{The Developmental Character of $\mathbf{C P}$}

Brain lesions place infants at risk for cerebral palsy. Unilateral cerebral palsy (UCP), the most common form, arises from unilateral brain injury and consequently results in motor impairments predominantly lateralized to the contralateral side. Such unilateral impairment often leads to children not using the affected extremity which induces "developmental disuse" of the affected limb (Charles \& Gordon, 2005), and thus, restricting the child's ability to perform bimanual tasks (Green et al., 2013), especially those requiring RDBM.

The most prevalent lesion in children with UCP is damage to the periventricular white matter (18-47\% of children with UCP) and is associated with preterm parturition (Reid, Dagia, Ditchfield, Carlin, \& Reddihough, 2014). These lesions occur between prenatal weeks 24 to 34 (Jaspers, Byblow, Feys, \& Wenderoth, 2016; Krageloh-Mann \& Horber, 2007) and result in damage to the corticospinal tract (CST) and the internal capsule. Formation and refinement of the afferent tracts (i.e., thalamocortical) occurs after the developmental period associated with PV lesions (Kostovic \& Jovanov-Milosevic, 2006). Thus, the sensory tracts are less affected than the efferent tracts in children with PV lesions (Guzzetta et al., 2007; Wilke et al., 2009). Other common lesions include damage to the cortical gray matter, the basal ganglia, and thalamus (20-30\% of children with UCP; Reid et al., 2014). These lesions tend to occur in the 4-5 weeks just prior to birth, after thalamocortical projections have reached the cortex, and thus, result in severe impairments in somatosensory function (Gupta et al., 2017; Staudt, 2010).

The role that brain lesions play in disrupting motor control has been predominantly examined in terms of their effects on the functioning of the CST. The CST is considered the principal motor pathway involved in the control of skilled manual actions. Damage to this system, driven by loss of direct projections from motor cortex to spinal cord motor circuits, leads to significant motor impairments. In children with UCP, aberrant CST connectivity contributes to deficits in the control of the contralateral limb, impairments in force production, and poor digit control (Forssberg, Eliasson, Redon-Zouitenn, Mercuri, \& Dubowitz, 1999; Gordon \& Duff, 1999; Hung, Charles, \& Gordon, 2004). In addition to loss of function, CST damage during early development can lead to presence of atypical patterns of movement, including spasticity, hyperreflexia, and mirror movements. 
This is an author-produced, peer-reviewed version of this article. The final, definitive version of this document can be found online at Cortex, published by Elsevier. Copyright restrictions may apply. doi: 10.1016/j.cortex.2020.02.017

In a feline model of CST development, activity-dependent competition between hemispheres shapes the organization of projecting CST axons. During early development, CST axons project bilaterally from the cerebral hemispheres to the spinal cord. This period is followed by a rapid reduction of ipsilateral projections and refinement of the contralateral organization that predominates in adults (Alisky, Swink, \& Tolbert, 1992; Theriault \& Tatton, 1989). Silencing activity from M1 enhances the effectiveness of the opposing, more active hemisphere (Friel \& Martin, 2007). The increased competitive advantage afforded by the silenced side permits the non-involved active side to maintain bilateral CST connectionsincluding aberrant ipsilateral connections that produce impairments in limb control (Friel \& Martin, 2007).

Neurophysiological studies of children with UCP also demonstrated that a perinatal neurological insult results in decreased excitability of the damaged CST, with concurrent increases in excitability of the hemisphere contralateral to the injured (i.e., ipsilateral to the affected upper-extremity) hemisphere (Eyre, 2007). It has been proposed that maintenance of aberrant ipsilateral CST connections in children with UCP is a result of similar activity-dependent mechanisms that were described in animal models of unilateral impairment. It is unknown what activity at the behavioral level contributes to the type of neural activity that refines lateral organization of the CST in children. However, longitudinal studies in typically developing infants suggest that even within the first 6 months of life, pronounced differences begin to emerge between contralateral and ipsilateral responses evoked by transcranial magnetic stimulation (TMS); ipsilateral responses have higher thresholds, longer latencies, and smaller amplitudes than contralateral responses (Eyre, Taylor, Villagra, Smith, \& Miller, 2001).

Since typical development involves a progressive reorganization from bilateral connectivity to predominantly contralateral connectivity (prior to the onset of skilled RDBM activities), early sensorimotor experiences that are functionally distinct from behaviors typically associated with the CST (e.g., grasping), may play an important role in refinement of motor pathways. Such experiences may include, but are not limited to, asymmetrical vestibular stimulation in utero, differential visual regard of the two hands associated with neonatal head orientation preferences, or asymmetries in spontaneous movements of the two hands. More importantly, identifying the specific experiences that shape the same activity-dependent processes that lead to abnormal movement outcomes in the context of injury might also be harnessed to rescue CST connectivity. The motor system exhibits an extraordinary flexibility to adapt to early brain injury.

Activity-dependent competition also exists between primary motor and sensory systems. Following unilateral pyramidal tract section or M1 ablation in rodents, proprioceptive afferents sprout into cervical gray matter regions denervated by CST terminations (Gibson, Arnott, \& Clowry, 2000; Tan, Chakrabarty, Kimura, \& Martin, 2012). These structural changes in the spinal cord are reflected by a depression of the H-reflex (i.e., hyperreflexia; Tan et al., 2012). Hyperreflexia and spasticity are common among children with CP and cause movement limitations (Cans, 2000; Flamand, Masse-Alarie, \& Schneider, 2013). In contrast to the motor system, somatosensory adaptation to injury is less robust. This is due in part to the fact that sensory connections are established very early in development, prior to the typical time of brain injury in CP. For reasons unknown, sensory projections (unlike the motor projections) do not reorganize in response to injury, leaving sensory function severely compromised (Wilke et al., 2009). Disruption of sensory function in children with brain injury creates a unique developmental trajectory, in which motor behaviors (e.g., spontaneous movements) may not have the same sensory consequence that they might have in typically developing children (e.g., lateral refinement of sensorimotor systems).

\section{The Corpus Callosum and CP}

The brain damage associated with CP occurs as the CC is developing and long before the development of the CC is sufficient for it to engage in the sophisticated interhemispheric communication needed to ensure the shaping and maintenance of hemispheric specialization. Recognition of this developmental sequence means that remedial therapeutic techniques must focus on facilitating the development of the functions of the CC either directly or via other interhemispheric communication techniques (e.g., use of other commissures, cross-cuing strategies, expansion of ipsilateral control, enhancement of contralateral and ipsilateral feedback).

Structural Differences. Neuroimaging studies have tried to chart the topographic map of the corpus callosum in relation to pre- and perinatal brain injury (Davatzikos, Barzi, Lawrie, Hoon, \& Melheim, 2003; Moses et al., 2000). Thus, using in vivo MRI, Moses et al. (2000) found a reduction in the area of the corpus callosum in children with brain lesions, with the area of the colossal cross-section being inversely proportional to the area of the lesion. Using MRI, researchers also found that children with CP usually have a smaller corpus callosum than their typically 
This is an author-produced, peer-reviewed version of this article. The final, definitive version of this document can be found online at Cortex, published by Elsevier. Copyright restrictions may apply. doi: 10.1016/j.cortex.2020.02.017

developing peers (Davatzikos et al., 2003; Kułak, Sobaniec, Kubas, \& Walecki, 2007). Thus, the corpus callosum surface area of children with CP was, on average, $26 \%$ smaller than that of typically developing controls (Kułak et al., 2007). These studies might suggest the lack of developmental neuroplasticity in corpus callosal structural integrity after early brain insult in children at risk for, or with, CP (but also see Santhouse et al., 2002; Serrien, Nirkko, \& Wiesendanger, 2001).

Sensorimotor Outcomes. In children with CP, a smaller mean corpus callosum surface area was significantly associated with inferior motor functioning on the Palisano et al. (1997) Gross Motor Function Classification System (Hayakawa et al, 1996; Kułak et al., 2007). Degeneration of the corpus callosum would likely affect children's performance in bimanual tasks (Chiarello, 1980; Jeeves, 1965, 1986; Sacco, Moutard, \& Fagard, 2006; Sauerwein, Lassonde, Cardu, \& Geoffroy, 1981). For example, children with CP who had greater white matter integrity of callosal fibers were better at performing the temporal aspects of a RDBM task (Hung, Robert, Friel, \& Gordon, 2019). Similarly, the performance of 12-month-old infants with agenesis of the corpus callosum (ACC) on a unimanual grasping task was not significantly impaired compared to their typically developing peers; whereas, their performance on a bimanual task was significantly impaired (Sacco et al., 2006). Such results suggest that any disruptions of CC development during infancy may interfere with the establishment of bimanual coordination and the lateralization of function (de Guise et al., 1999). Thus, children with CP might experience difficulties in bimanual coordination not only because of unilateral brain lesion, but also because of sub-optimal interhemispheric transfer via an underdeveloped CC.

Previous research proposed that the anterior CC is involved in bilateral co-ordination in motor and visuo-motor tasks, especially those requiring simultaneous/parallel processing and timely adjustment of movements performed by the two hands (Jeeves et al., 1988; Preilowski, 1972, 1975). Note that acquisition of the new motor skills often requires bimanual coordination of parallel movements and learning of ordered sequences, both heavily depending on interhemispheric transfer (and inhibition of mirror movements) via the CC (Andres \& Gerloff, 1999; Jeeves et al., 1988; Preilowski, 1972; Serrien \& Brown, 2003; Sperry, 1968; Sun, Miller, Rao, \& D’Esposito, 2006). Thus, underdeveloped CC, typical in those with CP, might interfere with their bimanual performance, implementation of finely-timed sequences of actions, and motor learning in general. These effects, emerging early in development, are likely to have cascading negative consequences for performance of functional activities at later ages-activities which are likely to be bimanual (e.g., buttoning shirt, tying shoes).

Cognitive Outcomes. A smaller mean CC surface area in children with CP was linked to lower verbal IQ scores on the Wechsler Intelligence Scale (Kułak et al., 2007). Moreover, both right- and left-hemiplegia children showed diminished nonverbal function compared to age-matched controls (Carlsson et al., 1994). In children with periventricular leukomalacia, the extent of brain lesion, as well as thinning of both anterior and posterior areas of the CC were significantly associated with children's verbal and performance scores of the Wechsler Intelligence Scale, with the performance scores being more affected (Fedrizzi et al., 1996). In children with unilateral or bilateral spastic $\mathrm{CP}$, verbal cognition was not significantly different from the norms established for typically developing children. However, sustained and divided attention, inhibition, shifting, and executive function in general were significantly impaired (Bottcher et al., 2010). It was proposed that lesions to the white matter might disrupt the connectivity among different brain areas, which is the basis of executive functions. Obviously, disorders in attention, common in children with $\mathrm{CP}$, often lead to learning difficulties and cognitive delays.

Since the Wechsler performance scores typically lag behind the Wechsler verbal scores in children with CP (e.g., Fedrizzi et al., 1996; Sigurdardottir et al., 2008), it was proposed that periventricular leukomalacia in children with CP might be linked to limitations in fine-motor manipulation, integration of visual and manual information, spatial representation, and in visuo-perceptual functions in general (Fedrizzi et al., 1996). Such visuo-perceptual impairments might be at the foundation of learning disabilities and cognitive delays often reported in children with CP.

Children with CP are delayed in their subitizing2 (Arp \& Fagard, 2005; Arp, Taranne, \& Fagard, 2006), counting (van Rooijen, Verhoeven, \& Steenbergen, 2011), and arithmetic skills (Jenks et al., 2007). For subitizing, children with CP were found to have a developmental trajectory qualitatively similar to that of typically developing children, but significantly delayed. Perhaps, the delayed subitizing stems from impaired visuo-spatial short-term memory, a deficit in pattern recognition, and an inability to perceive spatial patterns as a Gestalt (Arp \& Fagard, 2005). Poor arithmetic performance was found to be significantly associated with non-verbal, but not verbal, intelligence (Jenks et al., 2007; Jenks, van Lieshout, \& de Moor, 2009). Moreover, poor mathematical competence in children with CP was related to poor executive functions, such as shifting among tasks and remembering/updating information (Jenks et al., 2007). 
This is an author-produced, peer-reviewed version of this article. The final, definitive version of this document can be found online at Cortex, published by Elsevier. Copyright restrictions may apply. doi: 10.1016/j.cortex.2020.02.017

Although the development of mathematical literacy in children with CP might be impeded because of impairments in their visuo-spatial abilities, often attributed to right-hemisphere specialization (Arp \& Fagard, 2005; Filho, Souza, Nunes, Braga, \& Dellatolas, 2005; Kiessling, Denckla, \& Carlton, 1983; van Rooijen et al., 2011), these studies need replication using assessments based upon descriptions of hemispheric specialization derived from notions of sophisticated information processing strategies, as we noted above.

Laterality in $\mathbf{C P}$. Laterality of the brain lesion in children with $\mathrm{CP}$ was also shown to affect performance on intelligence tests. Despite similar scores on Wechsler Verbal IQ test, children with left hemiplegia (right hemisphere damage) and controls outperformed children with right hemiplegia (left hemisphere damage) on measures of "syntactic awareness" and "repetition of semantically coherent material" (Kiessling et al., 1983). Children with righthemiplegia exhibited impaired learning and recall of abstract drawings compared to controls (Carlsson, 1997). Furthermore, left-hand impairment in children with infantile hemiplegia was associated with poor arithmetic computational skills (Filho et al., 2005; Kiessling et al., 1983). Again, these studies need to be repeated with assessment of hemispheric specialization derived from the more sophisticated notions of information processing strategies.

Embodied Cognition in Children with CP. Embodied cognition theory (Barsalou, 2008; Thelen \& Smith, 1996; Wilson, 2002), proposes that the development of cognition stems from early sensorimotor skills, experiences, and activities of the person. Therefore, impaired posture, locomotion, arm movement, and their consequences on sensory feedback, ought to be associated with impaired cognitive functioning. Impairment of fine-motor manipulation of objects might lead to limited opportunities to manipulate objects and explore the world (Bertenthal \& von Hofsten, 1998; Campos et al., 2000; Thelen \& Spenser, 1998; van der Meer, van der Weel, \& Lee, 1995), establish hand-eye coordination (Atkinson \& Braddick, 207; Corbetta \& Snap- Childs, 2009; McCarty \& Ashmead, 1999; van Beck, Hopkins, Hoeksma, \& Samson, 1994), and practice visuo-spatial skills (Marcinowski, Nelson, Campbell, \& Michel, 2019). Such delayed visuo-spatial abilities might concatenate in children with CP into the learning difficulties, impaired non-verbal intelligence, and delays in the development of mathematical skills that they exhibit (Arp \& Fagard, 2005; Filho et al., 2005; Kiessling et al., 1983; van Rooijen et al., 2011). Importantly, impairment of finemotor manual movements and finger recognition/discrimination might impede not only the development of numerical abilities (Fayol, Barrouillet, \& Marinthe, 1998; Noël, 2005) but also the establishment of a hand-use preference for RDBM which likely plays an important role in hemispheric specialization (Michel et al., 2013b). Interestingly, an early hand preference for RDBM predicts better performance on standardized language assessments of production and comprehension at 2 and 3 years of age (Nelson, Campbell, \& Michel, 2013a; Nelson et al., 2017).

Thus, disruptions in CC development and the role that manual actions play in the establishment of hemispheric specialization are obvious consequences of $\mathrm{CP}$, and these likely are responsible for many of the developmental delays and deficits exhibited by children with CP. Attention to CC development and the development of hemispheric specialization should prompt the design of more effective remedial therapies.

\section{Future Directions}

Therapeutic interventions with children with CP should be derived from knowledge of how typical development contributes to the establishment of the hemispheric specialization that seems to be essential for efficient functioning. Encouraging the use of the affected limb and facilitating bimanual actions are important but we need to know exactly why such encouragement should be adopted and what consequences derive from that experience for the development of other functions. Importantly, because of the variability in CP etiology and manifestation, some therapies might be appropriate for some types of $\mathrm{CP}$, but not for others.

For example, interventions with "sticky mittens"3 (Libertus, Joh, \& Needham, 2015; Needham, Barrett, \& Peterman, 2002) or exoskeletons (Babik, Cunha, \& Lobo, 2019a; Babik et al., 2019b) might help children with CP who struggle with low muscle tone. Whereas "sticky mittens" deliver a more distal support at the hand, the Playskin provides a more proximal assistance at the shoulder. The "sticky mittens" might allow a higher level of object engagement and a more sophisticated object exploration in the absence of fine-motor movements in the affected hand (Needham et al., 2002). On the other hand, the Playskin LiftTM (Playskin) exoskeletal garment might offer the anti-gravity support, extend the child's reaching space, facilitate visual-manual coupling and bimanual reaching, as well as improve the multimodality, variability, and intensity of the exploratory play behaviors (Babik et al., 2019a, 2019b). However, the Playskin garment might be ineffective in cases involving high levels of spasticity (the snug fit of the garment might over-stimulate the child with spastic CP and lead to hyper extension at various joints). In addition, both "sticky 
This is an author-produced, peer-reviewed version of this article. The final, definitive version of this document can be found online at Cortex, published by Elsevier. Copyright restrictions may apply. doi: 10.1016/j.cortex.2020.02.017

mittens" and the Playskin devices might not facilitate independent, unassisted object play in children with hemiplegia: without the explicit, external encouragement, children with hemiplegia might continue disregarding the affected limb.

Understanding the ways early sensorimotor experience affects neuromotor development will help clinical researchers devise techniques to structure the postnatal environment so as to optimize movement. Technological improvements in characterizing movement patterns provide an unprecedented opportunity to monitor activity across time (Smith, Vanderbilt, Applequist, \& Kyvelidou, 2017) and in increasingly naturalistic settings (for review see Lobo et al., 2019). Information gleaned from longitudinal studies of movement patters both in typical and atypical development should reveal the best ways to structure practice, provide feedback, and promote self-initiated movement.

A growing body of evidence demonstrates the benefit of prompting self-initiated movement and task-specific training (Hadders-Algra 2014, Morgan et al., 2016). Interventions that promote variable patterns of movement (Lewek et al., 2009) and afford infants the opportunity to learn from their own experiences and errors in movement (Prosser, Pierce, Dillingham, Bernbaum, \& Jawad, 2018) are likely to have the largest benefit. In severe cases of movement limitations, assistive technologies that facilitate motor experiences might promote development across functional domains. Robotic devices that assist infants in learning to crawl (Ghazi et al., 2016) or explore the environment (Logan, Hospodar, Feldner, Huang, \& Galloway, 2018) might help mimic the types of motor experiences that promote cognitive development but only if these interventions are derived not from intuition, but from empirical evidence demonstrating that such experiences affect cognitive development.

Young children with CP exhibit reduced patterns of variability when acquiring motor skills, and thus, likely miss the typical opportunities that variations in experience provide in the acquisition of more sophisticated coordinated movements. Knowledge of how typical development permits exploration, variable experience, flexibility of movement patterns, and specialization of neural systems will provide a framework for developing therapies that optimize the potential of a highly plastic motor system. As we become more sophisticated in characterizing hemispheric specialization and the neuromotor control of movements including the experiences that they generate, we will become more sophisticated about the best ways to remediate the consequences of the early brain damage that results in CP.

Declaration of Interest Statement: The authors declare no conflict of interest.

\section{References}

Abbs, J. H., \& Grecco, V. L. (1983). Sensorimotor actions in the control of multi-movement speech gestures. Trends in Neuroscience, 6, 391-396.

Alisky, J. M., Swink, T. D., \& Tolbert, D. L. (1992). The postnatal spatial and temporal development of corticospinal projections in cats. Experimental Brain Research, 88(2), 265-276.

Andres, F. G., \& Gerloff, C. (1999). Coherence of sequential movements and motor learning. Journal of Clinical Neurophysiology, 16(6), 520.

Antoine, M. W., Zhu, X., Dieterich, M., Brandt, T., Vijayakumar, S., McKeehan, N., ... Hébert, J. M. (2018). Early uneven ear input induces long-lasting differences in left-right motor function. PLOS Biology, 16(3), e2002988. doi:10.1371/journal.pbio.2002988

Arbib, M. A. (2006). The mirror system hypothesis on the linkage of action and languages. In M. A. Arbib (Ed.), Action to language via the mirror neuron system (pp. 3-47). New York: Cambridge University Press.

Arbib, M. A. (2011). From mirror neurons to complex imitation in the evolution of language and tool use. Annual Review of Anthropology, 40, 257-273.

Arp, S., \& Fagard, J. (2005). What impairs subitizing in cerebral palsied children? Developmental Psychobiology, 47(1), 89-102.

Arp, S., Taranne, P., \& Fagard, J. (2006). Global perception of small numerosities (subitizing) in cerebral-palsied children. Journal of Clinical \& Experimental Neuropsychology, 28(3), 405-419.

Atkinson, J., \& Braddick, O. (2007). Visual and visuocognitive development in children born very prematurely. From Action to Cognition, 164, 123-149. doi: 10.1016/S0079-6123(07)64007-2

Babik, I., Cunha, A. B., \& Lobo, M. A. (2019a). Play with objects in children with arthrogryposis: Effects of intervention with the Playskin Lift ${ }^{\mathrm{TM}}$ exoskeletal garment. American Journal of Medical Genetics Part C: Seminars in Medical Genetics, 181, 393-403. doi: 10.1002/ajmg.c.31719

Babik, I., Cunha, A. B., Moeyaert, M., Hall, M. L., Paul, D. A., Mackley, A., \& Lobo, M. A. (2019b). Feasibility and effectiveness of intervention with the Playskin Lift exoskeletal garment for infants at risk. Physical Therapy, 6(99), 666-676. doi: 10.1093/ptj/pzz035 
This is an author-produced, peer-reviewed version of this article. The final, definitive version of this document can be found online at Cortex, published by Elsevier. Copyright restrictions may apply. doi: 10.1016/j.cortex.2020.02.017

Babik, I., \& Michel, G. F. (2016). Development of role-differentiated bimanual manipulation in infancy: Part 2. Hand preferences for object acquisition and RDBM - continuity or discontinuity? Developmental Psychobiology, 58, 257-267. doi: 10.1002/dev.21378

Badzakova-Trajkov, G., Häberling, I. S., Roberts, R. P., \& Corballis, M. C. (2010). Cerebral asymmetries: Complementary and independent processes. PLoS One, 5, e9682.

Barrett, T. M., Traupman, E., \& Needham, A. (2008). Infants' visual anticipation of object structure in grasp planning. Infant Behavior \& Development, 31, 1-9. doi: 10.1016/j.infbeh.2007.05.004

Barsalou, L. W. (2008). Grounded cognition. Annual Review of Psychology, 59, 617-645.

Bates, E., \& Dick, F. (2002). Language, gesture, and the developing brain. Developmental Psychobiology, 40, 293310.

Bates, E., O’Connell, B., Vaid, J., Sledge, P., \& Oakes, L. (1986). Language and hand preference in early development. Developmental Neuropsychology, 2, 1-15.

Bekoff, A. (1992). Neuroethological approaches to the study of motor development in chicks: Achievements and challenges. Journal of Neurobiology, 23(10), 1486-1505. doi:10.1002/neu.480231009

Bertenthal, B. I., \& von Hofsten, C. (1998). Eye, head and trunk control: The foundation for manual development. Neuroscience \& Biobehavioral Reviews, 22, 515-520. doi: 10.1016/S0149-7634(97)00038-9

Bethmann, A., Tempelmann, C., De Bleser, R., Scheich, H., \& Brechmann, A. (2007). Determining language laterality by fMRI and dichotic listening. Brain Research, 1133, 145-157.

Best, C. T., \& Avery, R. A. (1999). Left-hemisphere advantage for click consonants is determined by linguistic significance and experience. Psychological Science, 10, 65-70.

Bleyenheuft, Y., \& Gordon, A. M. (2013). Precision grip control, sensory impairments and their interactions in children with hemiplegic cerebral palsy: A systematic review. Research in Developmental Disabilities, 34(9), 3014-3028. doi:10.1016/j.ridd.2013.05.047

Blumberg, M. S., Freeman, J. H., \& Robinson, S. R. (2009). Oxford handbook of developmental behavioral neuroscience. Oxford University Press, USA.

Bottcher, L., Flachs, E. M., \& Uldall, P. (2010). Attentional and executive impairments in children with spastic cerebral palsy. Developmental Medicine \& Child Neurology, 52(2), e42-e47.

Boyd, R. N., Jordan, R., Pareezer, L., Moodie, A., Finn, C., Luther, B.,... Guzzetta, A. (2013). Australian cerebral palsy child study: Protocol of a prospective population based study of motor and brain development of preschool aged children with cerebral palsy. BMC Neurology, 13, 57. doi:10.1186/1471-2377-13-57

Bradley, N. S. (1997). Reduction in buoyancy alters parameters of motility in E9 chick embryos. Physioogy \& Behavior, 62(3), 591-595.

Brumley, M. R., \& Robinson, S. R. (2010). Experience in the perinatal development of action systems. In M. S. Blumberg, J. H. Freeman, \& S. R. Robinson (Eds.), Oxford handbook of developmental behavioral neuroscience (pp. 181-209). Oxford University Press.

Campbell, J. M., Marcinowski, E. C., Babik, I., \& Michel, G. F. (2015b). The influence of a hand-use preference for acquiring objects on the development of a hand-use preference for unimanual manipulation from 6 to 14 months. Infant Behavior \& Development, 39, 107-117. doi: 10.1016/j.infbeh.2015.02.013

Campbell, J. M., Marcinowski, E. C., Latta, J., \& Michel, G. F. (2015a). Different assessment tasks produce different estimates of handedness stability during the eight to 14-month age period. Infant Behavior \& Development, 39, 67-80.

Campos, J. J., Anderson, D. I., Barbu-Roth, M. A., Hubbard, E. M., Hertenstein, M. J., \& Witherington, D. (2000). Travel broadens the mind. Infancy, 1(2), 149-219.

Cans, C. (2000). Surveillance of cerebral palsy in Europe: A collaboration of cerebral palsy surveys and registers. Surveillance of Cerebral Palsy in Europe (SCPE). Developmental Medicine \& Child Neurology, 42(12), 816-824.

Carlsson, G. (1997). Memory for words and drawings in children with hemiplegic cerebral palsy. Scandinavian Journal of Psychology, 38(4), 265-273.

Carlsson, G., Uvebrant, P., Hugdahl, K., Arvidsson, J., Wiklund, L. M., \& von Wendt, L. (1994). Verbal and nonverbal function of children with right-versus left-hemiplegic cerebral palsy of pre-and perinatal origin. Developmental Medicine \& Child Neurology, 36(6), 503-512.

Carr, L. J., Harrison, L. M., Evans, A. L., \& Stephens, J. A. (1993). Patterns of central motor reorganization in hemiplegic cerebral palsy. Brain, 116(5), 1223-1247.

Casasanto, D. (2009). Embodiment of abstract concepts: Good and bad in right- and left-handers. Journal of Experimental Psychology: General, 138, 351-367. 
This is an author-produced, peer-reviewed version of this article. The final, definitive version of this document can be found online at Cortex, published by Elsevier. Copyright restrictions may apply. doi: 10.1016/j.cortex.2020.02.017

Charles, J., \& Gordon, A. M. (2005). A critical review of constraint-induced movement therapy and forced use in children with hemiplegia. Neural Plastisity, 12(2-3), 245-261; discussion 263-272. doi:10.1155/NP.2005.245

Chiarello, C. (1980). A house divided? Cognitive functioning with callosal agenesis. Brain and Language, 11(1), 128-158.

Cioni, G., Ferrari, F., Einspieler, C., Paolicelli, P. B., Barbani, T., \& Prechtl, H. F. (1997). Comparison between observation of spontaneous movements and neurologic examination in preterm infants. Journal of Pediatrics, 130(5), 704-711.

Cooper, W. E., \& Paccia-Cooper, J. (1980). Syntax and speech (No. 3). Harvard University Press.

Corballis, M. C. (1991). The lopsided ape. NewYork: Oxford University Press.

Corballis, M. C. (2003). From mouth to hand: gesture, speech, and the evolution of right-handedness. Behavioral \& Brain Sciences, 26(2), 199-208.

Corballis, M. C. (2010). Handedness and cerebral asymmetry: An evolutionary perspective. In K. Hughdahl \& R. Weaterhausen (Eds.), The two halves of the brain (pp. 65-88). Cambridge, MA: The MIT Press.

Corballis, M. C. (2015). What's left in language? Beyond the classical model. Annals of the New York Academy of Sciences, 1359, 14-29.

Corballis, M. C. (2017). The evolution of lateralized brain circuits. Frontiers in Psychology, 8, 1021.

Corbetta, M. (2012). Functional connectivity and neurological recovery. Developmental Psychobiology, 54(3), 239253.

Corbetta, D., \& Snapp-Childs, W. (2009). Seeing and touching: The role of sensory-motor experience on the development of infant reaching. Infant Behavior \& Development, 32, 44-58. doi: 10.1016/j.infbeh.2008.10.004

Corbetta, D., Thurman, S. L., Wiener, R. F., Guan, Y., \& Williams, J. L. (2014). Mapping the feel of the arm with the sight of the object: on the embodied origins of infant reaching. Frontiers in Psychology, 5, 576.

Corina, D. P. (1998). Aphasia in users of signed languages. In P. Coppens et al. (Eds.), Aphasia in atypical populations (pp. 261-309). Erlbaum.

Davatzikos, C., Barzi, A., Lawrie, T., Hoon, A. H., \& Melhem, E. R. (2003). Correlation of corpus callosal morphometry with cognitive and motor function in periventricular leukomalacia. Neuropediatrics, 34(05), 247-252.

Davidson, R. J. (1992). Emotion and affective style: Hemispheric substrates. Psychological Science, 3, 39-43.

Deco, G., Tononi, G., Boly, M., \& Kringelbach, M. L. (2015). Rethinking segregation and integration: Contributions of whole-brain modelling. Nature Reviews Neuroscience, 16, 430-439.

de Guise, E., del Pesce, M., Foschi, N., Quattrini, A., Papo, I., \& Lassonde, M. (1999). Callosal and cortical contribution to procedural learning. Brain, 122(6), 1049-1062.

Demaree, H. A., Everhart, D. E., Youngstrom, E. A., \& Harrison, D. W. (2005). Brain lateralization of emotional processing: Historical roots and a future incorporating "dominance". Behavioral and Cognitive Neuroscience Reviews, 4, 3-20.

Deutsch, D. (1985). Dichotic listening to melodic patterns and its relationship to hemispheric specialization of function. Music Perception, 3, 127-154.

De Vries, J. I., Visser, G. H., \& Prechtl, H. F. (1982). The emergence of fetal behaviour. I. Qualitative aspects. Early Human Development, 7(4), 301-322.

de Vries, J. I. P., Wimmers, R. H., Ververs, I. A. P., Hopkins, B., Savelsbergh, G. J. P., \& Van Geijn, H. P. (2001). Fetal handedness and head position preference: A developmental study. Developmental Psychobiology, 39, 171-178.

Efron, R., Koss, B., \& Yund, E. W. (1983). Central auditory processing IV. Ear dominance - spatial and temporal complexity. Brain and Language, 19, 264-282.

Emmorey, K., Grabowski, T, McCullough, S., Damasio, H., Ponto, L. L., Hichwa, R. D., \& Bellugi, U. (2003). Neural systems underlying lexical retrieval for sign language. Neuropsychologia, 41, 85-95.

Emmorey, K., Mehta, S., \& Grabowski, T. J. (2007). The neural correlates of sign versus word production. Neuroimage, 36, 202-208.

Esseily, R., Jacquet, A.-Y., \& Fagard, J. (2011). Handedness for grasping objects and pointing and the development of language in 14-month-old infants. Laterality, 16, 565-585.

Eyre, J. A. (2007). Corticospinal tract development and its plasticity after perinatal injury. Neuroscience \& Biobehavioral Reviews, 31(8), 1136-1149. doi: 10.1016/j.neubiorev.2007.05.011

Eyre, J. A., Taylor, J. P., Villagra, F., Smith, M., \& Miller, S. (2001). Evidence of activity-dependent withdrawal of corticospinal projections during human development. Neurology, 57(9), 1543-1554. 
This is an author-produced, peer-reviewed version of this article. The final, definitive version of this document can be found online at Cortex, published by Elsevier. Copyright restrictions may apply. doi: 10.1016/j.cortex.2020.02.017

Fagard, J., \& Corroyer, D. (2003). Using a continuous index of laterality to determine how laterality is related to interhemispheric transfer and bimanual coordination in children. Developmental Psychobiology, 43, 44-56.

Fayol, M., Barrouillet, P., \& Marinthe, C. (1998). Predicting arithmetical achievement from neuro-psychological performance: A longitudinal study. Cognition, 68(2), B63-B70.

Fedrizzi, E., Inverno, M., Bruzzone, M. G., Botteon, G., Saletti, V., \& Farinotti, M. (1996). MRI features of cerebral lesions and cognitive functions in preterm spastic diplegic children. Pediatric Neurology, 15(3), 207-212.

Ferre, C. L., Babik, I., \& Michel, G. F. (2010). Development of infant prehension handedness: a longitudinal analysis during the 6- to 14-month age period. Infant Behavior \& Development, 33(4), 492-502. doi:10.1016/j.infbeh.2010.06.002

Ferre, C. L., \& Gordon, A. M. (2017). Coaction of individual and environmental factors: A review of intensive therapy paradigms for children with unilateral spastic cerebral palsy. Developmental Medicine \& Child Neurology, 59(11), 1139-1145.

Fetters, L., Sapir, I., Chen, Y. P., Kubo, M., \& Tronick, E. (2010). Spontaneous kicking in full-term and preterm infants with and without white matter disorder. Developmental Psychobiology, 52(6), 524-536.

Filho, G. N., Souza, L., Nunes, L. G., Braga, L. W., \& Dellatolas, G. (2005). Manual skill, hand skill asymmetry, and neuropsychological test performance in schoolchildren with spastic cerebral palsy. Laterality: Asymmetries of Body, Brain and Cognition, 10(2), 161-182.

Flamand, V. H., Masse-Alarie, H., \& Schneider, C. (2013). Psychometric evidence of spasticity measurement tools in cerebral palsy children and adolescents: A systematic review. Journal of Rehabilitation Medicine, 45(1), 14-23. doi:10.2340/16501977-1082

Fong, B. F., Savelsbergh, G. J. P., Van Geijn, H. P., \& De Vries, J. I. P. (2005). Does intra-uterine environment influence fetal head-position preference? A comparison between breech and cephalic presentation. Early Human Development, 81(6), 507-517.

Forssberg, H., Eliasson, A. C., Redon-Zouitenn, C., Mercuri, E., \& Dubowitz, L. (1999). Impaired grip-lift synergy in children with unilateral brain lesions. Brain, 122 (6), 1157-1168.

Franco, F., \& Butterworth, G. (1996). Pointing and social awareness: Declaring and requesting in the second year. Journal of Child Language, 23, 307-336.

Frey, S. H. (2014). Tool use, communicative gestures and cerebral asymmetries in the modern human brain. Philosophical Transactions of the Royal Society B, 363, 1951-1957.

Friel, K. M., \& Martin, J. H. (2007). Bilateral activity-dependent interactions in the developing corticospinal system. Journal of Neuroscience, 27(41), 11083-11090. doi:10.1523/jneurosci.2814-07.2007

Gardner, H., Brownell, H., Wapner, W., \& Michelow, D. (1983). Missing the point: The role of the right hemisphere in processing complex linguistic materials. In E. Perecman (Ed.), Cognitive processing in the right hemisphere (pp. 169-191). NY: Academic Press.

Gazzaniga, M. S. (2000). Cerebral specialization and interhemispheric communication: Does the corpus callosum enable the human condition? Brain, 123, 1293-1326.

Gazzaniga, M. S., Ivry, R. B., \& Mangun, G. R. (2009). Cognitive neuroscience: The biology of the mind (3rd ed.). New York: W. W. Norton \& Company, Inc.

Ghazi, M. A., Nash, M. D., Fagg, A. H., Ding, L., Kolobe, T. H., \& Miller, D. P. (2016). Novel assistive device for teaching crawling skills to infants. In D. S. Wettergreen \& T. D. Barfoot (Eds.), Field and service robotics (pp. 593-605). Springer, Cham.

Gibson, C. L., Arnott, G. A., \& Clowry, G. J. (2000). Plasticity in the rat spinal cord seen in response to lesions to the motor cortex during development but not to lesions in maturity. Experimental Neurology, 166(2), 422434. doi:10.1006/exnr.2000.7511

Giedd, J. N., Blumenthal, J., Jeffries, N. O., Rajapakse, J. C., Vaituzis, A. C., Liu, H., ... Castellanos, F. X. (1999). Development of the human corpus callosum during childhood and adolescence: A longitudinal MRI study. Progress in Neuro-Psychopharmacology and Biological Psychiatry, 23, 571-588.

Godfrey, H. K., \& Grimshaw, G. M. (2016). Emotional language is all right: Emotional prosody reduces hemispheric asymmetry for linguistic processing. Laterality, 21, 568-584.

Goldin-Meadow, S., \& D. McNeill. (1999). The role of gesture and mimetic representation in making language the province of speech. In M. C. Corballis \& S. E. G. Lea (Eds.), The descent of mind (pp. 155-172). Oxford, UK: Oxford University Press.

Gordon, A. M., \& Duff, S. V. (1999). Relation between clinical measures and fine manipulative control in children with hemiplegic cerebral palsy. Developmental Medicine \& Child Neurology, 41(9), 586-591. 
This is an author-produced, peer-reviewed version of this article. The final, definitive version of this document can be found online at Cortex, published by Elsevier. Copyright restrictions may apply. doi: 10.1016/j.cortex.2020.02.017

Green, D., Schertz, M., Gordon, A. M., Moore, A., Schejter Margalit, T., Farquharson, Y., ... Fattal-Valevski, A. (2013). A multi-site study of functional outcomes following a themed approach to hand-arm bimanual intensive therapy for children with hemiplegia. Developmental Medicine \& Child Neurology, 55(6), 527533.

Greenfield, P. (2006). Implications of mirror neurons for the ontogeny and phylogeny of cultural processes: The examples of tools and language. In M. A. Arbib (Ed.), Action to language via the mirror neuron system (pp. 501-533). Cambridge: Cambridge University Press.

Güntürkün, O., \& Ocklenburg, S. (2017). Ontogenesis of lateralization. Neuron, 94, 249-263.

Gupta, D., Barachant, A., Gordon, A. M., Ferre, C., Kuo, H. C., Carmel, J. B., \& Friel, K. M. (2017). Effect of sensory and motor connectivity on hand function in pediatric hemiplegia. Annals of Neurology, 82(5), 766780. doi:10.1002/ana.25080

Guzzetta, A., Bonanni, P., Biagi, L., Tosetti, M., Montanaro, D., Guerrini, R., \& Cioni, G. (2007). Reorganisation of the somatosensory system after early brain damage. Clinical Neurophysiology, 118(5), 1110-1121. doi:10.1016/j.clinph.2007.02.014

Hadders-Algra, M. (2014). Early diagnosis and early intervention in cerebral palsy. Frontiers in Neurology, 5, 185.

Hayakawa, K., Kanda, T., Hashimoto, K., Okuno, Y., Yamori, Y., Yuge, M., ... Tamamoto, A. (1996). MR imaging of spastic diplegia: The importance of corpus callosum. Acta Radiologica, 37(3P2), 830-836.

Hellige, J. B. (1993). Hemispheric asymmetry: What's right and what's left. Cambridge, MA: Harvard University Press.

Hepper, P. G., McCartney, G., \& Shannon, E. A. (1998). Lateralised behaviour in first trimester human fetuses. Neuropsychologia, 36, 531-534.

Hepper, P. G., Shahidullah, S., \& White, R. (1991). Handedness in the human fetus. Neuropsychologia, 29, 11011111.

Hepper, P. G., Wells, D. L., \& Lynch, C. (2005). Prenatal thumb sucking is related to postnatal handedness. Neuropsychologia, 43, 313-315.

Hickok, G., Bellugi, U, \& Klima, E. S. (1998). The neural organization of language: Evidence from sign language aphasia. Trends in Cognitive Sciences, 2, 129-136

Hood, K. E., Halpern, C. T., Greenberg, G., \& Lerner, R. M. (2010). Developmental systems, nature-nurture, and the role of genes in behavior and development. In K. E. Hood (Ed.), Handbook of developmental science, behavior, and genetics (pp. 1-12). Malden, MA: Wiley-Blackwell.

Hopkins, B., \& Rönnqvist, L. (1998). Human handedness: Developmental and evolutionary perspectives. In F. Simeon \& G. Butterworth (Eds.), The development of sensory, motor and cognitive capacities in early infancy: From sensation to cognition (pp. 191-236). Hove, UK: Psychology Press.

Hung, Y. C., Charles, J., \& Gordon, A. M. (2004). Bimanual coordination during a goal-directed task in children with hemiplegic cerebral palsy. Developmental Medicine \& Child Neurology, 46(11), 746-753.

Hung, Y. C., Robert, M., Friel, K., \& Gordon, A. (2019). Relationship between integrity of the corpus callosum and bimanual coordination in children with Unilateral Spastic Cerebral Palsy. Frontiers in Human Neuroscience, 13, 334.

Isaacs, K. L., Barr, W. B., Nelson, P. K., \& Devinsky, O. (2006). Degree of handedness and cerebral dominance. Neurology, 66, 1855-1858.

Islam, M., Nordstrand, L., Holmström, L., Kits, A., Forssberg, H., \& Eliasson, A.-C. (2014). Is outcome of constraint-induced movement therapy in unilateral cerebral palsy dependent on corticomotor projection pattern and brain lesion characteristics? Developmental Medicine \& Child Neurology, 56(3), 252-258. doi:10.1111/dmcn.12353

Iverson, J. M., \& Goldin-Meadow, S. (2005). Gesture paves the way for language. Science, 304, 1682-1683.

Jacquet, A.-Y., Esseily, R., Rider, D., \& Fagard, J. (2012). Handedness for grasping objects and declarative pointing: A longitudinal study. Developmental Psychobiology, 54, 36-46.

Jaspers, E., Byblow, W. D., Feys, H., \& Wenderoth, N. (2016). The corticospinal tract: A biomarker to categorize upper limb functional potential in unilateral cerebral palsy. Frontiers in Pediatrics, 3(112). doi:10.3389/fped.2015.00112

Jeeves, M. A. (1965). Psychological studies of three cases of congenital agenesis of the corpus callosum. In A. V. S. De Reuch (Ed.), Functions of the corpus callosum (pp. 73-94). London: Churchill.

Jeeves, M. A. (1986). Callosal agenesis: Neuronal and developmental adaptations. In F. Lepore, M. Ptito, \& H. H. Jasper (Eds.), Two hemispheres, one brain: Functions of the corpus callosum (pp. 403-422). New York: Alan R. Liss. 
This is an author-produced, peer-reviewed version of this article. The final, definitive version of this document can be found online at Cortex, published by Elsevier. Copyright restrictions may apply. doi: 10.1016/j.cortex.2020.02.017

Jeeves, M. A., Silver, P. H., \& Milne, A. B. (1988). Role of the corpus callosum in the development of a bimanual motor skill. Developmental Neuropsychology, 4, 305-323.

Jenks, K. M., de Moor, J., van Lieshout, E. C., Maathuis, K. G., Keus, I., \& Gorter, J. W. (2007). The effect of cerebral palsy on arithmetic accuracy is mediated by working memory, intelligence, early numeracy, and instruction time. Developmental Neuropsychology, 32(3), 861-879.

Jenks, K. M., van Lieshout, E. C., \& de Moor, J. (2009). The relationship between medical impairments and arithmetic development in children with cerebral palsy. Journal of Child Neurology, 24(5), 528-535.

Kiessling, L. S., Denckla, M. B., \& Carlton, M. (1983). Evidence for differential hemispheric function in children with hemiplegic cerebral palsy. Developmental Medicine \& Child Neurology, 25(6), 727-734.

Kimura, D. (1973). The asymmetry of the human brain. Scientific American, 228, 70-78.

Kinsbourne, M. (1975). The ontogeny of cerebral dominance. Annals of the New York Academy of Sciences, 263, 244-250.

Kleven, G. A., Lane, M. S., \& Robinson, S. R. (2004). Development of interlimb movement synchrony in the rat fetus. Behavioral Neuroscience, 118(4), 835-844. doi:10.1037/0735-7044.118.4.835

Knecht, S., Deppe, M., Dräger, B., Bobe, L., Lohmann, H., Ringelstein, E., \& Henningsen, H., (2000a). Language lateralization in healthy right-handers. Brain, 123, 74-81.

Knecht, S., Dräger, B., Deppe, M., Bobe, L., Lohmann, H., Flöel, A., ... Henningsen, H. (2000b). Handedness and hemispheric language dominance in healthy humans. Brain, 123, 2512-2518.

Knyazeva, M. G., \& Farber, D. A. (1991). Fornation of interhemispheric interaction in ontogeny: Electrophysiological analysis. Human Physiology, 17, 1-11.

Kolb, B., \& Teskey, G. C. (2012). Age, experience, injury, and the changing brain. Developmental Psychobiology, 54(3), 311-325.

Kostovic, I., \& Jovanov-Milosevic, N. (2006). The development of cerebral connections during the first 20-45 weeks' gestation. Seminars in Fetal and Neonatal Medicine, 11(6), 415-422. doi:10.1016/j.siny.2006.07.001

Krageloh-Mann, I., \& Horber, V. (2007). The role of magnetic resonance imaging in elucidating the pathogenesis of cerebral palsy: A systematic review. Developmental Medicine \& Child Neurology, 49(2), 144-151. doi:10.1111/j.1469-8749.2007.00144.x

Kudo, N., Nishimaru, H., \& Nakayama, K. (2004). Developmental changes in rhythmic spinal neuronal activity in the rat fetus. Progress in Brain Research, 143, 49-55.

Kuhnke, N., Juenger, H., Walther, M., Berweck, S., Mall, V., \& Staudt, M. (2008). Do patients with congenital hemiparesis and ipsilateral corticospinal projections respond differently to constraint-induced movement therapy? Developmental Medicine \& Child Neurology, 50(12), 898-903. doi:10.1111/j.14698749.2008.03119.x

Kułak, W., Sobaniec, W., Kubas, B., \& Walecki, J. (2007). Corpus callosum size in children with spastic cerebral palsy: Relationship to clinical outcome. Journal of Child Neurology, 22(4), 371-374.

Lenneberg, E. H. (1967). Biological foundations of language. New York: John Wiley \& Sons, Inc.

Levine, S. C., Banich, M. T., \& Koch-Weser, M. P. (1988). Face recognition: A general or specific RH capacity? Brain and Cognition, 8, 303-325.

Lewek, M. D., Cruz, T. H., Moore, J. L., Roth, H. R., Dhaher, Y. Y., \& Hornby, T. G. (2009). Allowing intralimb kinematic variability during locomotor training poststroke improves kinematic consistency: A subgroup analysis from a randomized clinical trial. Physical Therapy, 89(8), 829-839. doi:10.2522/ptj.20080180

Liberman, A. M., \& Mattingly, I. G. (1985). The motor theory of speech perception revised. Cognition, 21(1), 1-36.

Libertus, K., Joh, A. S., \& Needham, A. W. (2016). Motor training at 3 months affects object exploration 12 months later. Developmental Science, 19(6), 1058-1066.

Lobo, M. A., \& Galloway, J. C. (2008). Postural and object-oriented experiences advance early reaching, object exploration, and means-end behavior. Child Development, 79(6), 1869-1890.

Lobo, M. A., Hall, M. L., Greenspan, B., Rohloff, P., Prosser, L. A., \& Smith, B. A. (2019). Wearables for pediatric rehabilitation: How to optimally design and use products to meet the needs of users. Physical Therapy, 99(6), 647-657. doi:10.1093/ptj/pzz024

Logan, S. W., Hospodar, C. M., Feldner, H. A., Huang, H. H., \& Galloway, J. C. (2018). Modified ride-on car use by young children with disabilities. Pediatric Physical Therapy, 30(1), 50-56. doi:10.1097/pep.0000000000000468

MacNeilage, P. F., Rogers, L. J., \& Vallortigara, G. (2009). Origins of the left and right brain. Scientific American, 301, 60-67. 
This is an author-produced, peer-reviewed version of this article. The final, definitive version of this document can be found online at Cortex, published by Elsevier. Copyright restrictions may apply. doi: 10.1016/j.cortex.2020.02.017

Marshall, J., Atkinson, J., Smulovitch, E., Thacker, A., \& Woll, B. (2004). Aphasia in a user of British Sign Language: Dissociation between sign and gesture. Cognitive Neuropsychology, 21, 537-554.

Marcinowski, E. C., Nelson, E., Campbell, J. M., \& Michel, G. F. (2019). The development of object construction from infancy through toddlerhood. Infancy, 24(3), 368-391. doi: 10.1111/infa.12284

McCarty, M. E, \& Ashmead, D. H. (1999). Visual control of reaching and grasping in infants. Developmental Psychology, 35, 620-631. doi: 10.1037/0012-1649.35.3.620

McNeill, D. (2012). How language began: Gesture and speech in human evolution. Cambridge, UK: Cambridge University Press.

Meyer, B., Röricht, S., Gräfin von Einsiedel, H., Kruggel, F., \& Weindl, A. (1995). Inhibitory and excitatory interhemispheric transfers between motor cortical areas in normal humans and patients with abnormalities of the corpus callosum. Brain, 118, 429-440.

Michel, G. F. (1983). Development of hand-use preference during infancy. In G. Young, S. Segalowitz, C. Corter, \& S. Trehub (Eds.), Manual specialization and the developing brain (pp. 33-70). New York: Academic Press.

Michel, G. F. (1988). A neuropsychological perspective on infant sensorimotor development. In C. Rovee-Collier \& L. P. Lipsitt (Eds.), Advances in infancy research (vol. 5, pp. 1-38). Norwood, NJ: Ablex.

Michel, G. F. (1991). Development of infant manual skills: Motor programs, schemata, or dynamic systems? In J. Fagard \& P. H. Wolff (Eds.), Advances in Psychology (vol. 81, pp. 175-199): North-Holland.

Michel, G. F. (1998). A lateral bias in the neuropsychological functioning of human infants. Developmental Neuropsychology, 14, 445-469.

Michel, G. F. (2002). Development of infant handedness. In D. J. Lewkowicz \& R. Lickliter (Eds.), Conceptions of development: Lessons from the laboratory (pp. 165-186). New York: Psychology Press.

Michel, G. F. (2007). Doing what comes naturally: The role of self generated experience in behavioral development. European Journal of Developmental Science, 1(2), 155-164.

Michel, G. F. (2010). The roles of environment, experience, and learning in behavioral development. In K. Hood, C. Halpern, G. Greenberg, \& R. Lerner (Eds.) Handbook of Developmental Science, Behavior and Genetics (pp. 123-165). Malden, MA: Wiley

Michel, G. F. (2012). Using knowledge of development to promote recovery of function after brain damage. Developmental Psychobiology, 54(3), 350-356.

Michel, G. F. (2018). How might the relation of the development of hand preference to the development of cognitive functions be examined during infancy: A sketch? Frontiers of Neuroscience, 11:739. doi: 10.3389/fnins.2017.00739

Michel, G. F., Babik, I., Nelson, E. L., Campbell, J. M., \& Marcinowski, E. C. (2013a). How the development of handedness could contribute to the development of language. Developmental Psychobiology, 55(6), 608620. doi: 10.1002/dev.21121

Michel, G. F., \& Goodwin, R. (1979). Intrauterine birth position predicts newborn supine head position preferences. Infant Behavior \& Development, 2, 29-38. doi: 10.1016/S0163-6383(79)80005-3

Michel, G. F., \& Harkins, D. A. (1986). Postural and lateral asymmetries in the ontogeny of handedness during infancy. Developmental Psychobiology, 19(3), 247-258. doi:10.1002/dev.420190310

Michel, G. F., \& Moore, C. L. (1995). Developmental psychobiology: An interdisciplinary science. Cambridge, MA: The MIT Press.

Michel, G. F., Nelson, E. L., Babik, I., Campbell, J. M., \& Marcinowski, E. C. (2013b). Multiple trajectories in the developmental psychobiology of human handedness. In R. M. Lerner \& J. B. Benson (Eds.), Embodiment and epigenesis: Theoretical and methodological issues in understanding the role of biology within the relational developmental system. Part B: Ontogenetic Dimensions (pp. 227-260). Elsevier Inc.: Academic Press.

Michel, G. F., \& Tyler, A. N. (2005). Critical period: A history of the transition from questions of when, to what, to how. Developmental Psychobiology, 46(3), 156-162.

Moen, I. (1993). Functional lateralization of the perception of Norwegian word tones - Evidence from a dichotic listening experiment. Brain and Language, 44, 400-413.

Morgan, C., Darrah, J., Gordon, A. M., Harbourne, R., Spittle, A., Johnson, R., \& Fetters, L. (2016). Effectiveness of motor interventions in infants with cerebral palsy: A systematic review. Developmental Medicine \& Child Neurology, 58(9), 900-909. doi:10.1111/dmcn.13105

Morgan, M. (1977). Embryology and inheritance of asymmetry. In S. Harnad et al. (Eds.) Lateralization in the nervous system (pp. 173-194). New York: Academic Press.

Moses, P., Courchesne, E., Stiles, J., Trauner, D., Egaas, B., \& Edwards, E. (2000). Regional size reduction in the human corpus callosum following pre-and perinatal brain injury. Cerebral Cortex, 10(12), 1200-1210. 
This is an author-produced, peer-reviewed version of this article. The final, definitive version of this document can be found online at Cortex, published by Elsevier. Copyright restrictions may apply. doi: 10.1016/j.cortex.2020.02.017

Mutch, L., Alberman, E., Hagberg, B., Kodama, K., \& Perat, M. V. (1992). Cerebral palsy epidemiology: Where are we now and where are we going? Developmental Medicine \& Child Neurology, 34(6), 547-551.

Needham, A., Barrett, T., \& Peterman, K. (2002). A pick-me-up for infants’ exploratory skills: Early simulated experiences reaching for objects using 'sticky mittens' enhances young infants' object exploration skills. Infant Behavior \& Development, 25(3), 279-295.

Nelson, E. L., Campbell, J. M., \& Michel, G. F. (2013a). Early handedness in infancy predicts language ability in toddlers. Developmental Psychobiology, 50, 809-814. doi: 10.1037/a0033803

Nelson, E. L., Campbell, J. M., \& Michel, G. F. (2013b). Unimanual to bimanual: Tracking the development of handedness from 6 to 24 months. Infant Behavior \& Development, 36, 181-188.

Nelson, E. L., Gonzalez, S. L., Coxe, S., Campbell, J. M., Marcinowski, E. C., \& Michel, G. F. (2017). Toddler hand preference trajectories predict 3-year language outcome. Developmental Psychobiology, 59, 876-887. doi: 10.1002/dev. 21560

Noël, M. P. (2005). Finger gnosia: A predictor of numerical abilities in children? Child Neuropsychology, 11(5), 413-430.

Ojemann, G. A. (1984). Common cortical and thalamic mechanisms for language and motor functions. American Journal of Physiology, 246, R901-R903.

Oldfield, R. C. (1971). The assessment and analysis of handedness: The Edinburgh Inventory. Neuropsychologia, 9, 97-113.

Oztop, E., Arbib, M. A., \& Bradley, N. (2006). The development of grasping and the mirror system. In M. A. Arbib (Ed.), Action to language via the mirror neuron system (pp. 397-423). New York: Cambridge University Press.

Palisano, R., Rosenbaum, P., Walter, S., Russell, D., Wood, E., \& Galuppi, B. (1997). Development and reliability of a system to classify gross motor function in children with cerebral palsy. Developmental Medicine \& Child Neurology, 39(4), 214-223. doi:10.1111/j.1469-8749.1997.tb07414.x

Pandya, D. N., Karol, E. A., \& Heilbronn, D. (1971). The topographical distribution of interhemispheric projections in the corpus callosum of the rhesus monkey. Brain Research, 32(1), 31-43.

Patterson, K., \& Bradshaw, J. L. (1975). Differential hemispheric mediation of nonverbal visual stimuli. Journal of Experimental Psychology: Human Performance, 1, 246-252.

Peelle, J. E. (2012). The hemispheric lateralization of speech processing depends on what "speech" is: A hierarchical perspective. Frontiers in Human Neuroscience, 6, 309.

Petitto, L. A., Zatorre, R. J., Gauna, K., Nikelski, E. J., Dostie, D., \& Evans, A. C. (2000). Speech-like cerebral activity in profoundly deaf people while processing signed languages: Implications for the neural basis of all human language. Proceedings of the National Academy of Sciences, 97, 13961-13966.

Preilowski, B. F. (1972). Possible contribution of the anterior forebrain commissures to bilateral motor coordination. Neuropsychologia, 10(3), 267-277.

Preilowski B. F. (1975). Bilateral motor interaction: Perceptual-motor performance of partial and complete 'splitbrain’ patients. In K. J. Zülch, O. Creutzfeld, \& G. C. Galbraith (Eds.), Cerebral localization (pp. 115-132). Berlin: Springer.

Previc, F. H. (1991). A general theory concerning the prenatal origins of cerebral lateralization in humans. Psychological Review, 98(3), 299-334.

Prosser, L. A., Pierce, S. R., Dillingham, T. R., Bernbaum, J. C., \& Jawad, A. F. (2018). iMOVE: Intensive Mobility training with Variability and Error compared to conventional rehabilitation for young children with cerebral palsy: The protocol for a single blind randomized controlled trial. BMC Pediatr, 18(1), 329-329. doi:10.1186/s12887-018-1303-8

Pujol, J., Vendrell, P., Junqué, C., Larti-Vilalta, J. L., \& Capdevila, A. (1993). When does human brain development end? Evidence of corpus callosum growth up to adulthood. Annals of Neurology, 34, 71-75.

Ramsay, D. S. (1985). Fluctuations in unimanual hand preference in infants following the onset of duplicated syllable babbling. Developmental Psychology, 21, 318-324.

Reid, S. M., Dagia, C. D., Ditchfield, M. R., Carlin, J. B., \& Reddihough, D. S. (2014). Population-based studies of brain imaging patterns in cerebral palsy. Developmental Medicine \& Child Neurology, 56(3), 222-232. doi:10.1111/dmcn.12228

Robinson, S. R. (2016). Yoke motor learning in the fetal rat: A model system for prenatal behavioral development. In N. Reissland \& B. S. Kisilevsky (Eds.), Fetal development: Research on brain and behavior, environmental influences, and emerging technologies (pp. 43-66). Cham: Springer International Publishing. 
This is an author-produced, peer-reviewed version of this article. The final, definitive version of this document can be found online at Cortex, published by Elsevier. Copyright restrictions may apply. doi: 10.1016/j.cortex.2020.02.017

Rochat, P., \& Bullinger, A. (1994). Posture and functional action in infancy. In A. Vyt, H. Bloch, \& M. H. Bornstein (Eds.), Early child development in the French tradition: Contributions from current research (pp. 15-34). Hillsdale, NJ: Erlbaum.

Rogers, L. J., Vallortigara, G., \& Andrew, R. J. (2013). Divided brains: The biology and behaviour of brain asymmetries. Cambridge University Press, New York.

Rogers, L. J., Zucca, P., \& Vallortigara, G. (2004). Advantages of having a lateralized brain. Proceedings of the Royal Society B: Biological Sciences, 271, S420-S422.

Ronca, A. E., Kamm, K., Thelen, E., \& Alberts, J. R. (1994). Proximal control of fetal rat behavior. Developmental Psychobiology, 27(1), 23-38. doi:10.1002/dev.420270104

Rosenbaum, P., Paneth, N., Leviton, A., Goldstein, M., Bax, M., Damiano, D., ... Jacobsson, B. (2007). A report: The definition and classification of cerebral palsy April 2006. Developmental Medicine \& Child Neurology. Supplement, 109, 8-14.

Sacco, S., Moutard, M. L., \& Fagard, J. (2006). Agenesis of the corpus callosum and the establishment of handedness. Developmental Psychobiology, 48, 472-481.

Salamy, A. (1978). Commissural transmission: Maturational changes in humans. Science, 200, 1409-1411.

San José-Robertson, L., Corina, D. P., Ackerman, D., Guillemin, A., \& Braun, A. R. (2004). Neural systems for sign language production: Mechanisms supporting lexical selection, phonological encoding, and articulation. Human Brain Mapping, 23, 156-167.

Santhouse, A. M., Ffytche, D. H., Howard, R. J., Williams, S. C. R., Stewart, A. L., Rooney, M., ... Murray, R. M. (2002). The functional significance of perinatal corpus callosum damage: An fMRI study in young adults. Brain, 125(8), 1782-1792.

Sauerwein, H. C., Lassonde, M. C., Cardu, B., \& Geoffroy, G. (1981). Interhemispheric integration of sensory and motor functions in agenesis of the corpus callosum. Neuropsychologia, 19(3), 445-454.

Schnitzler, A., Kessler, K. R., \& Benecke, R. (1996). Transcallosally mediated inhibition of interneurons within human primary motor cortex. Experimental Brain Research, 112, 381-391.

Sergent, J. (1982a). About face: Left-hemisphere involvement in processing physiognomies. Journal of Experimental Psychology: Human Perception and Performance, 8, 1-14.

Sergent, J. (1982b). Basic determinants in visual-field effects with special reference to the Hannay et al. (1981) study. Brain and Language, 16, 158-164.

Sergent, J. (1982c). The cerebral balance of power: Confrontation or cooperation. Journal of Experimental Psychology: Human Perception and Performance, 8, 253-272.

Serrien, D. J., \& Brown, P. (2003). The integration of cortical and behavioural dynamics during initial learning of a motor task. European Journal of Neuroscience, 17(5), 1098-1104.

Serrien, D. J., Ivry, R. B., \& Swinnen, S. P. (2006). Dynamics of hemispheric specialization and integration in the context of motor control. Nature Reviews Neuroscience, 7, 160-166.

Serrien, D. J., Nirkko, A. C., \& Wiesendanger, M. (2001). Role of the corpus callosum in bimanual coordination: A comparison of patients with congenital and acquired callosal damage. European Journal of Neuroscience, 14(11), 1897-1905.

Shtyrov, Y., Pihko, E., \& Pulvermuller, F. (2005). Determinants of dominance: Is language laterality explained by physical or linguistic features of speech? Neuroimage, 27, 37-47.

Sigurdardottir, S., Eiriksdottir, A., Gunnarsdottir, E., Meintema, M., Arnadottir, U., \& Vik, T. (2008). Cognitive profile in young Icelandic children with cerebral palsy. Developmental Medicine \& Child Neurology, 50(5), 357-362.

Sival, D. A., Prechtl, H. F., Sonder, G. H., \& Touwen, B. C. (1993). The effect of intra-uterine breech position on postnatal motor functions of the lower limbs. Early Human Development, 32(2-3), 161-176.

Small, S. L., Buccino, G., \& Solodkin, A. (2012). The mirror neuron system and the treatment of stroke. Developmental Psychobiology, 54(3), 293-310. doi.org/10.1002/dev.20504

Smith, B. A., Vanderbilt, D. L., Applequist, B., \& Kyvelidou, A. (2017). Sample entropy identifies differences in spontaneous leg movement behavior between infants with typical development and infants at risk of developmental delay. Technologies, 5(3), 55. doi:10.3390/technologies5030055

Smith, L., \& Gasser, M. (2005). The development of embodied cognition: Six lessons from babies. Artificial Life, 11(1-2), 13-29. doi:10.1162/1064546053278973

Sperry, R. W. (1968). Hemisphere deconnection and unity in conscious awareness. American Psychologist, 23(10), 723.

Staudt, M. (2010). Brain plasticity following early life brain injury: Insights from neuroimaging. Seminars in Perinatology, 34(1), 87-92. doi:10.1053/j.semperi.2009.10.009 
This is an author-produced, peer-reviewed version of this article. The final, definitive version of this document can be found online at Cortex, published by Elsevier. Copyright restrictions may apply. doi: 10.1016/j.cortex.2020.02.017

Steele, J., \& Uomini, N. (2009). Can the archeology of manual specialization tell us anything about language evolution? A survey of the state of play. Cambridge Archaeological Journal, 19, 97-110.

Sun, F. T., Miller, L. M., Rao, A. A., \& D'Esposito, M. (2006). Functional connectivity of cortical networks involved in bimanual motor sequence learning. Cerebral Cortex, 17(5), 1227-1234.

Tan, A. M., Chakrabarty, S., Kimura, H., \& Martin, J. H. (2012). Selective corticospinal tract injury in the rat induces primary afferent fiber sprouting in the spinal cord and hyperreflexia. Journal of Neuroscience, 32(37), 12896-12908. doi:10.1523/jneurosci.6451-11.2012

Teulier, C., Lee, D. K., \& Ulrich, B. D. (2015). Early gait development in human infants: Plasticity and clinical applications. Developmental Psychobiology, 57(4), 447-458. doi:10.1002/dev.21291

Thatcher, R. W. (1980). Neurolinguistics: Theoretical and evolutionary perspectives. Brain and Language, 11, 235260.

Thelen, E., Corbetta, D., Kamm, K., Spencer, J. P., Schneider, K., \& Zernicke, R. F. (1993). The transition to reaching: Mapping intention and intrinsic dynamics. Child Development, 64(4), 1058-1098.

Thelen, E., Fisher, D. M., \& Ridley-Johnson, R. (2002). The relationship between physical growth and a newborn reflex. Infant Behavior \& Development, 25(1), 72-85.

Thelen, E., \& Smith, L. B. (1996). A dynamic systems approach to the development of cognition and action. MIT press.

Thelen, E., \& Spencer, J. P. (1998). Postural control during reaching in young infants: A dynamic systems approach. Neuroscience and Biobehavioral Reviews, 22(4), 507-514. doi: 10.1016/S0149-7634(97)00037-7

Theriault, E., \& Tatton, W. G. (1989). Postnatal redistribution of pericruciate motor cortical projections within the kitten spinal cord. Developmental Brain Research, 45(2), 219-237.

Thomas, B. L., Karl, J. M., \& Whishaw, I. Q. (2015). Independent development of the Reach and the Grasp in spontaneous self-touching by human infants in the first 6 months. Frontiers in Psychology, 5, 1526.

Uomini, N. T., \& Meyer G. F. (2013). Shared brain lateralization patterns in language and Acheulean stone tool production: A functional transcranial Doppler ultrasound study. PLoS One, 8, e72693.

Vallortigara, G., \& Rogers, L. J. (2005). Survival with an asymmetrical brain: Advantages and disadvantages of cerebral lateralization. Behavioral and Brain Sciences, 28, 575-589.

van Beck, Y., Hopkins, B., Hoeksma, J., \& Samson, J. F. (1994). Prematurity, posture, and the development of looking behavior during early communication. Journal of Child Psychology and Psychiatry, 35, 10931107. doi: 10.1111/j.1469-7610.1994.tb01811.x

van der Meer, A. L. H., van der Weel, F. R., \& Lee, D. N. (1995). The functional significance of arm movements in neonates. Science, 267(5198), 693-695. doi: 10.1126/science.7839147

Van der Meer, A. L., Van der Weel, F. R., \& Lee, D. N. (1995). The functional significance of arm movements in neonates. Science, 267(5198), 693-695.

van Rooijen, M., Verhoeven, L., \& Steenbergen, B. (2011). Early numeracy in cerebral palsy: Review and future research. Developmental Medicine \& Child Neurology, 53(3), 202-209.

Vauclair, J., \& Imbault, J. (2009). Relationship between manual preference for object manipulation and pointing gestures in infants and toddlers. Developmental Science, 12, 1060-1069.

Ververs, I. A., de Vries, J. I., van Geijn, H. P., \& Hopkins, B. (1994). Prenatal head position from 12-38 weeks. I. Developmental aspects. Early Human Development, 39, 83-91.

Wang, Y., Behne, D. M., Jongman, A., \& Sereno, J. A. (2004). The role of linguistic experience in the hemispheric processing of lexical tone. Applied Psycholinguistics, 25, 449-466.

Wang, Y., Jongman, A., \& Sereno, J. A. (2001). Dichotic perception of Mandarin tones by Chinese and American listeners. Brain and Language, 78, 332-348.

Weinstein, M., Green, D., Geva, R., Schertz, M., Fattal-Valevski, A., Artzi, M., ... Bashat, D. B. (2014). Interhemispheric and intrahemispheric connectivity and manual skills in children with unilateral cerebral palsy. Brain Struct Funct, 219(3), 1025-1040. doi:10.1007/s00429-013-0551-5

Willems, R. M., \& Hagoort, P. (2007). Neural evidence for the interplay between language, gesture, and action: A review. Brain and Language, 101, 278-289.

Willems, R. M., Hagoort, P., \& Casasanto, D. (2010). Body-specific representations of action verbs. Psychological Science, 21, 67-74.

Willems, R. M., Toni, I., Hagoort, P., \& Casasanto, D. (2009). Body-specific motor imagery of hand actions: Neural evidence from right- and left-handers. Frontiers in Human Neuroscience, 3, 39.

Wilke, M., Staudt, M., Juenger, H., Grodd, W., Braun, C., \& Krageloh-Mann, I. (2009). Somatosensory system in two types of motor reorganization in congenital hemiparesis: Topography and function. Human Brain Mapping, 30(3), 776-788. doi:10.1002/hbm.20545 
This is an author-produced, peer-reviewed version of this article. The final, definitive version of this document can be found online at Cortex, published by Elsevier. Copyright restrictions may apply. doi: 10.1016/j.cortex.2020.02.017

Wilson, M. (2002). Six views of embodied cognition. Psychonomic Bulletin \& Review, 9(4), 625-636.

Witelson, S. F. (1985). On hemisphere specialization and cerebral plasticity from birth: Mark II. In C. T. Best (Ed.), Hemispheric function and collaboration in the child (pp. 33-85). Academic Press, Inc.

Woytowicz, E. J., Westlake, K. P., Whitall, J., \& Sainburg, R. L. (2018). Handedness results from complementary hemispheric dominance, not global hemispheric dominance: evidence from mechanically coupled bilateral movements. Journal of Neurophysiology, 120(2), 729-740. doi:10.1152/jn.00878.2017
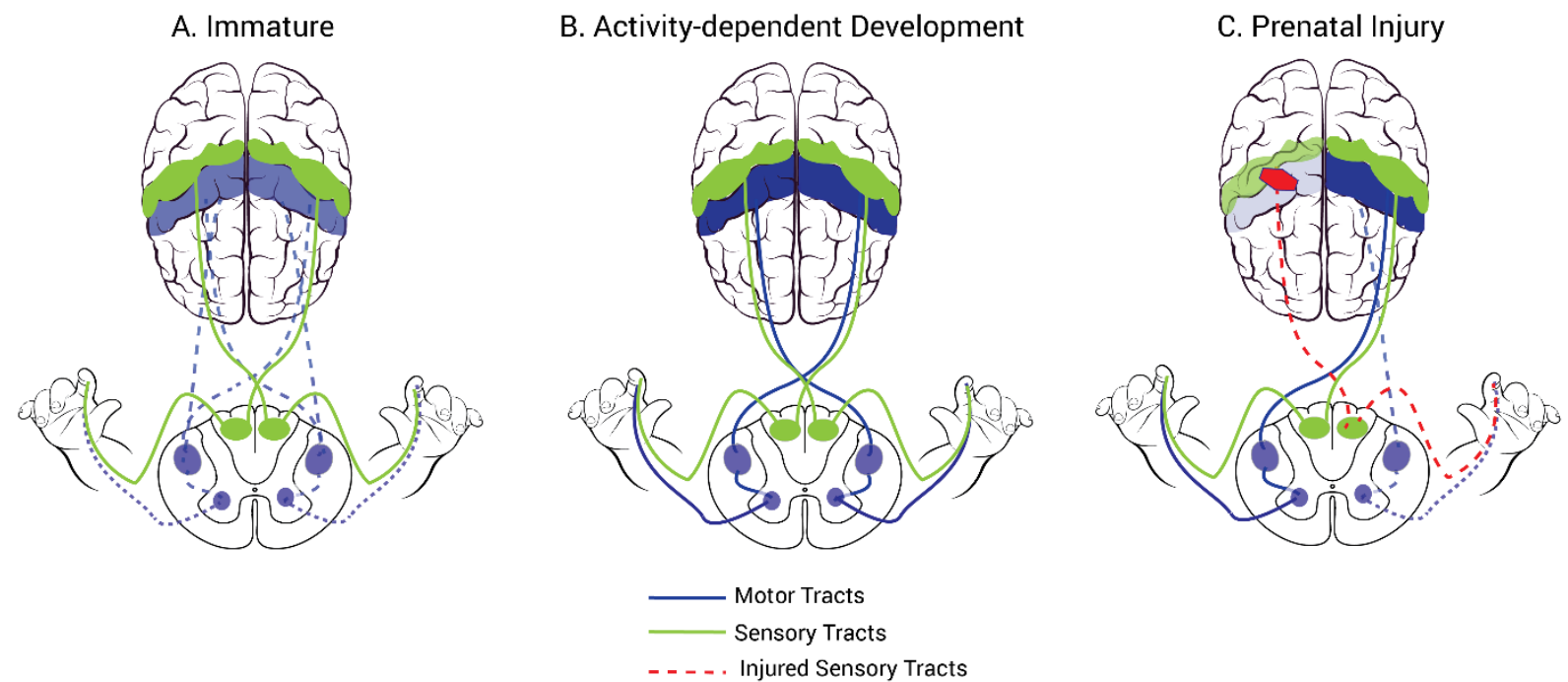

Figure 1. Schematic of activity-dependent (AD) development of sensory and motor pathways. A. Immature patterns during early development. Immature motor tracts (dashed blue) project to both sides of spinal cord. Sensory tracts (solid green) are already established at birth. B. Following AD development, ipsilateral motor tracts are pruned back and contralateral connections are strengthened. C. In a significant proportion of children with unilateral cortical injury, aberrant ipsilateral motor tracts from unaffected hemisphere persist and tracts from injured hemisphere are pruned. Relations to damaged sensory tracts (dashed red) from the injured hemisphere are not well known. 